Article

\title{
Transport Properties and Resistance Improvement of Ultra-High Performance Concrete (UHPC) after Exposure to Elevated Temperatures
}

\author{
Yunfeng Qian ${ }^{1}$, Dingyi Yang ${ }^{1,2, *}$, Yanghao Xia ${ }^{1}$, Han Gao ${ }^{1}$ and Zhiming Ma ${ }^{1,3}$ \\ 1 College of Civil Science and Engineering, Yangzhou University, Yangzhou 225127, China \\ yzu_qyf1996@163.com (Y.Q.); yanghaoxia2021@163.com (Y.X.); 15861562188@163.com (H.G.); \\ 006879@yzu.edu.cn (Z.M.) \\ 2 Research Institute of Green Building Materials, Yangzhou University, Yangzhou 225127, China \\ 3 Department of Structural Engineering, Tongji University, Shanghai 200092, China \\ * Correspondence: yangdy@yzu.edu.cn
}

Citation: Qian, Y.; Yang, D.; Xia, Y.; Gao, H.; Ma, Z. Transport Properties and Resistance Improvement of Ultra-High Performance Concrete (UHPC) after Exposure to Elevated Temperatures. Buildings 2021, 11, 416. https://doi.org/10.3390/buildings 11090416

Academic Editor: Pavel Reiterman

Received: 18 August 2021

Accepted: 14 September 2021

Published: 17 September 2021

Publisher's Note: MDPI stays neutral with regard to jurisdictional claims in published maps and institutional affiliations.

Copyright: (c) 2021 by the authors. Licensee MDPI, Basel, Switzerland. This article is an open access article distributed under the terms and conditions of the Creative Commons Attribution (CC BY) license (https:// creativecommons.org/licenses/by/ $4.0 /)$.

\begin{abstract}
Ultra-high performance concrete (UHPC) has a high self-healing capacity and is prone to bursting after exposure to high temperatures due to its characteristics. This work evaluates the damage and improvement of UHPC with coarse aggregates through mechanical properties (compressive strength and ultrasonic pulse velocity), transport properties (water absorption and a chloride diffusion test), and micro-properties such as X-ray diffraction (XRD), Mercury intrusion porosimetry (MIP), and Scanning electronic microscopy (SEM). The result demonstrates that polypropylene (PP) fibers are more suitable for high temperature tests than polyacrylonitrile (PAN) fibers. The result shows that $400{ }^{\circ} \mathrm{C}$ is the critical temperature point. With the increase in temperature, the hydration becomes significant, and the internal material phase changes accordingly. Although the total pore volume increased, the percentage of various types of pores was optimized within $400{ }^{\circ} \mathrm{C}$. The mass loss gradually increased and the ultrasonic pulse velocity gradually decreased. While the compressive strength first increased and then decreased, and the increase occurred within $25-400{ }^{\circ} \mathrm{C}$. As for the transport properties, the chloride migration coefficient and capillary absorption coefficient both increased dramatically due to the higher sensitivity to temperature changes. The results of the property improvement test showed that at temperatures above $800^{\circ} \mathrm{C}$, the compressive strength recovered by more than $65 \%$ and the ultrasonic pulse velocity recovered by more than $75 \%$. In terms of transport properties, compared to the results before self-healing, the chloride migration coefficient decreased by up to $59 \%$, compared with $89 \%$ for the capillary absorption coefficient, after self-healing at $800^{\circ} \mathrm{C}$. With respect to the enhancement effect after exposure to high temperatures, the environment of a $5 \% \mathrm{Na}_{2} \mathrm{SO}_{4}$ solution was not as good as the clean water environment. The corresponding changes in microstructure during the high temperatures and the self-healing process can explain the change in the pattern of macroscopic properties more precisely.
\end{abstract}

Keywords: ultra-high performance concrete; elevated temperatures; self-healing; transport properties

\section{Introduction}

With significant economic and performance advantages, ultra-high performance concrete (UHPC) has been gradually used in civil engineering structures such as high-rise buildings and bridges. As a dense internal microstructure can effectively reduce porosity and permeability, UHPC has excellent characteristics such as high strength and high durability [1-3]. Fire is one of the most severe hazards in tunnels, high-rise buildings, and underground construction. The burst of concrete is the most serious form of damage caused by the coupling of thermal stress, water vapor pressure, material decomposition, and other factors in the process of fire $[4,5]$. When a burst occurs, the concrete will rapidly decompose into random splashes of different sizes within a short period. Damaged concrete not only 
leaves reinforcing steel exposed and rapidly reduces the load-bearing capacity of the structure, but also causes unpredictable injuries to the escapees and rescuers. Consequently, the burst would produce significantly unexpected damage to both the concrete and surrounding environment $[6,7]$. Compared to ordinary concrete, UHPC has a lower water-cement ratio and lower porosity, which makes it more prone to burst at elevated temperatures, limiting its wide range of applications [8].

Adding polypropylene (PP) fiber to the concrete is the most common measure to inhibit the burst of concrete since the pores left by the melting PP fibers at elevated temperatures can effectively release internal vapor pressure [9-11]. Coarse aggregates can also have an impact on the burst because the addition of coarse aggregates would form a porous interface transition zone (ITZ). It is believed that the ITZ presented by the coarse aggregates can function together with the PP fiber melting pore to provide internal water vapor with a release channel $[12-14]$. Li et al. $[15,16]$ investigated the change in the pattern of the pore pressure and pore structure after exposure to high temperatures and found that the combination of PP fiber with steel fiber or PP fiber with coarser aggregates could effectively improve the permeability and ultimately inhibit the occurrence of burst. However, common UHPC depends on the principle of compact stacking, which eliminates coarse aggregates, and no obvious ITZ areas can be observed [17-19]. Related research shows that the steel fibers can improve the resistance of concrete to high temperatures, but cannot completely avoid the burst [20-22]. Other researchers have studied the joint action of PP fibers and steel fibers to prevent the burst of UHPC [23-25]. However, the actual mechanisms that serve to explain the improvement in the burst phenomenon have not been explained in a unified way. Moreover, in addition to PP fibers, it remains to be studied whether similar mechanisms and effects exist for other types of polymer fibers. Transport properties of UHPC after exposure to elevated temperatures have not been studied in depth.

Transport behavior is the primary means to evaluate the durability performance, which is related to the microstructure of cementitious composites and the invading solution ions [26]. Compared to the changes in mechanical properties, the adverse phenomena caused by high temperatures have a more significant degree of influence on the transport properties. The decline in transport properties would affect the resistance of concrete to the intrusion of exterior materials, ultimately causing deterioration in the durability performance of concrete structures. Hence, the transport property after exposure to elevated temperatures is one of the most critical indicators to evaluate phenomena such as internal moisture migration and pore pressure accumulation, which are related to the microstructure of cementitious composites and invasive solution ions [27,28]. Li et al. [23] found that adding PP fibers to concrete significantly increased the permeability without the burst, while steel fibers decreased the permeability and eventually burst. Poon et al. [29-31] found that the resistance of concrete to water and chloride ion penetration after exposure to high temperatures underwent a remarkable degradation, and the deterioration of high performance concrete was more serious.

Studies have demonstrated that post-fire treatment could result in a better improvement of relevant properties. A self-healing capability means that in the absence of external action, the moisture and other components of the atmosphere penetrate into the concrete to produce chemical reactions in it and generate substances to fill the gaps; thus, the concrete has the ability to recover its properties. Due to its own low water-cement ratio, a large amount of unhydrated cementitious material exists in UHPC. When cracks occur and external moisture intrudes, UHPC will have a higher potential self-healing ability than regular concrete, which can approach the undamaged groups in some properties [32,33]. Jiang et al. [34,35] showed that apparent cracks, mechanical properties, and permeability properties would be recovered. Nevertheless, for fire-damaged concrete, post-fire curing is a promising method to recover properties with a much lower cost. For example, Li et al. [36] found that the target temperature needed to exceed a specific value before demonstrating the recovery of the permeability properties effectively. The effect of post-fire curing as a 
self-healing method on the mechanical and transport properties of fire-damaged UHPC remains to be explored. When the water from outside penetrates inside, the unhydrated or partially hydrated cement particles in the concrete will undergo secondary hydration to produce C-S-H gels and other products, gradually healing the cracks through filling and cementation. In addition, in the presence of $\mathrm{Na}_{2} \mathrm{SO}_{4}, \mathrm{NaOH}$ is formed as a by-product of the reaction, which ensures the continuity of the high alkalinity of the concrete system that is crucial for the stability of the C-S-H gels.

Although scholars have conducted a lot of research on the high temperature performance of UHPC, the research results are inconsistent, and opposite conclusions have been. The, UHPC containing coarse aggregates and the enhancement of performance after exposure to high temperatures still need to be studied in depth. Therefore, the present work investigates the deterioration and recovery of the transport properties and mechanical properties of UHPC containing coarse aggregates after exposure to high temperatures. In the temperature experiments, the better synthetic fiber types were selected based on the burst performance. Then, the effect of high temperatures on the transport properties and mechanical properties of UHPC media was evaluated by water absorption, rapid chloride migration, and mechanical experiments. Further, microscopic properties were assessed by various microscopic testing techniques, which are beneficial to analyze the microstructure evolution at different temperatures. Finally, clean water and a $5 \% \mathrm{Na}_{2} \mathrm{SO}_{4}$ solution were selected to evaluate the effects of the self-healing environment on the relevant properties through water absorption, rapid chloride migration, and mechanical experiments. The self-healing products were determined by means of a microscopic test. This study also provides a feasible way to improve the resistance and mechanical properties of UHPC after exposure to elevated temperatures. The authors hope this work can help evaluate the post high-temperature mechanical properties and durability performance of UHPC.

\section{Materials and Experiments}

\subsection{Mix Proportions and Specimen Preparation}

The UHPC mix consisted of P.II 52.5 silicate cement, silica fume, fly ash, mechanism sand, river sand, 0-10 $\mathrm{mm}$ basalt aggregate, superplasticizer, polypropylene (PP) fibers, polyacrylonitrile (PAN) fibers, and steel fibers. Table 1 shows the main chemical composition of the cementitious materials. The main component of the superplasticizer was polycarboxylic acid. Table 2 shows the basic parameters of the fibers used.

Table 1. Chemical composition of the major materials.

\begin{tabular}{cccccc}
\hline \multirow{2}{*}{ Binder } & \multicolumn{5}{c}{ Main Oxide Types (\%) } \\
\cline { 2 - 6 } & $\mathbf{S i O}_{\mathbf{2}}$ & $\mathbf{A l}_{\mathbf{2}} \mathbf{O}_{\mathbf{3}}$ & $\mathbf{F e}_{\mathbf{2}} \mathbf{O}_{\mathbf{3}}$ & $\mathbf{C a O}$ & $\mathbf{M g O}$ \\
\hline Cement & 19.70 & 4.45 & 2.93 & 63.62 & 1.28 \\
Fly ash & 52.92 & 23.17 & 5.14 & 9.82 & 3.02 \\
Silica fume & 87.21 & 0.43 & 3.02 & 1.19 & 1.97 \\
\hline
\end{tabular}

Table 2. Main parameters of the fibers.

\begin{tabular}{cccccc}
\hline Fiber & $\begin{array}{c}\text { Density } \\
\left(\mathbf{g} / \mathbf{c m}^{\mathbf{3}}\right)\end{array}$ & $\begin{array}{c}\text { Diameter } \\
(\boldsymbol{\mu \mathbf { m } )}\end{array}$ & $\begin{array}{c}\text { Length } \\
\mathbf{( m \mathbf { m } )}\end{array}$ & $\begin{array}{c}\text { Tensile Strength } \\
\mathbf{( M P a )}\end{array}$ & $\begin{array}{c}\text { Elasticity Modulus } \\
(\mathbf{G P a})\end{array}$ \\
\hline Steel & 7.80 & 200.00 & 12.00 & 2100.00 & 210.00 \\
PP & 0.91 & 31.12 & 12.00 & 510.42 & 4.65 \\
PAN & 1.18 & 11.69 & 12.00 & 624.73 & 11.48 \\
\hline
\end{tabular}

The concrete water-cement ratio was 0.19 , and Table 3 shows the number and ratio of each group; the percentage replacement of cement with fly ash and silica fume was $20 \%$ and $10 \%$, respectively, and synthetic fibers were blended separately or mixed with steel fibers. Figure 1 shows the preparation process, and the whole process was characterized by several additions of raw materials and several mixing times. The specific operational requirements 
were as follows: first, the cementitious material was placed in the equipment, and the mixing time was set to $2 \mathrm{~min}$. Then, the aggregates were mixed with the cementitious material, and the mixing time was set to $1 \mathrm{~min}$. Next, the water and water reducing agents were placed in the equipment; the uniformity of the entire equipment needed to be noted and controlled during the addition, and the mixing time was set to $5 \mathrm{~min}$. Finally, the fibers were sieved and placed in the equipment to ensure their uniformity inside, and the mixing time was set to 3-5 min. In addition, if in any step the material was observed to collect in the corners or form clumps, it was necessary to stop the process and quickly shovel the material to the appropriate position with tools such as a shovel to achieve a uniform mix. The test specimens were all prepared to a size of $100 \times 100 \times 100 \mathrm{~mm}$. In each group, three samples were prepared for each property to be tested, according to the Chinese standard GB/T 31387-2015 "Reactive Powder Concrete" and the standard CECS 02: 2005 "Technical Specification for Detecting Strength of Concrete by the Ultrasonic-rebound Combined Method".

Table 3. Test mix ratios.

\begin{tabular}{|c|c|c|c|c|c|c|c|c|c|}
\hline \multirow{2}{*}{ No. } & \multicolumn{6}{|c|}{ Raw Material $\left(\mathrm{kg} / \mathrm{m}^{3}\right)$} & \multicolumn{3}{|c|}{ Fiber Content (\%) } \\
\hline & Cement & Fly Ash & Silica Fume & River Sand & Artificial Sand & Coarse Aggregate & Steel & PP & PAN \\
\hline PU & 630.00 & 180.00 & 90.00 & 476.00 & 84.00 & 742.33 & - & - & - \\
\hline UP & 630.00 & 180.00 & 90.00 & 476.00 & 84.00 & 742.33 & - & 0.30 & - \\
\hline UN & 630.00 & 180.00 & 90.00 & 476.00 & 84.00 & 742.33 & - & - & 0.30 \\
\hline US & 630.00 & 180.00 & 90.00 & 476.00 & 84.00 & 742.33 & 1.00 & - & - \\
\hline $\mathrm{SP}$ & 630.00 & 180.00 & 90.00 & 476.00 & 84.00 & 742.33 & 1.00 & 0.30 & - \\
\hline SN & 630.00 & 180.00 & 90.00 & 476.00 & 84.00 & 742.33 & 1.00 & - & 0.30 \\
\hline
\end{tabular}

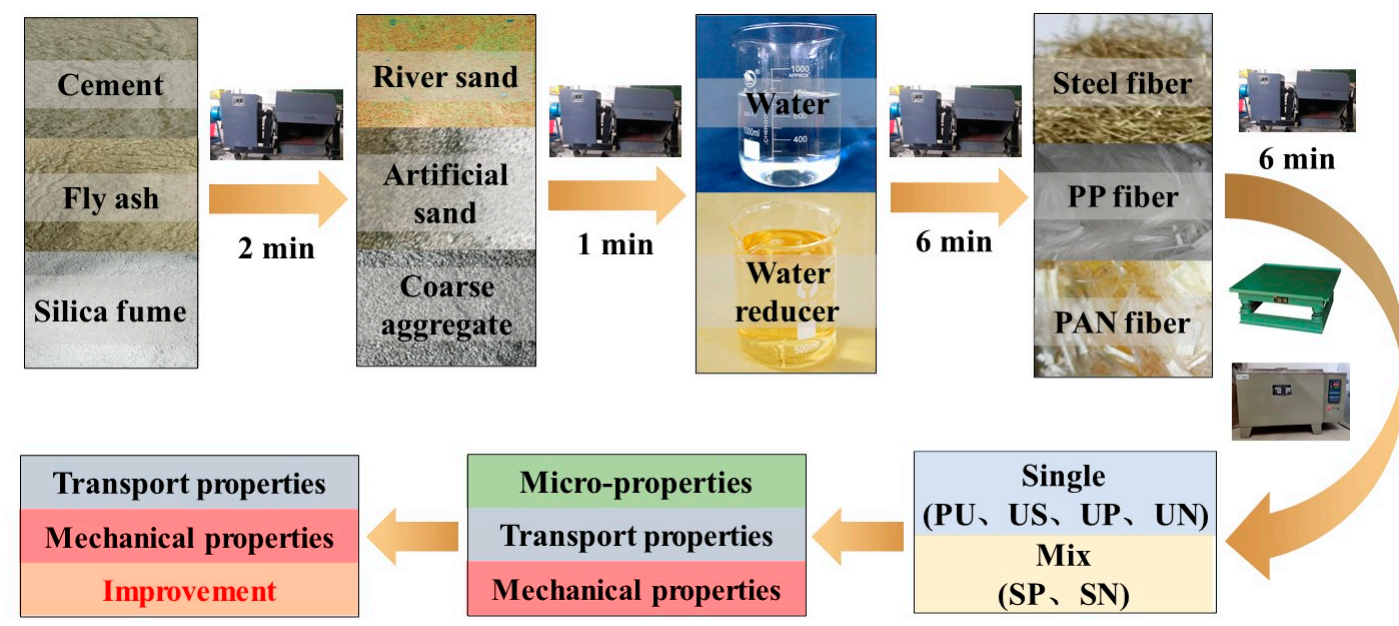

Figure 1. Mixing process of UHPC.

The specimens were cured by hot water at $90{ }^{\circ} \mathrm{C}$ for $72 \mathrm{~h}$, after which they were naturally cooled to room temperature. In the high temperature test, the specimens were pre-dried to a constant weight, and the heating rate was set as $5{ }^{\circ} \mathrm{C} / \mathrm{min}$. The target temperature was $200{ }^{\circ} \mathrm{C}, 400{ }^{\circ} \mathrm{C}, 600{ }^{\circ} \mathrm{C}$, and $800^{\circ} \mathrm{C}$, and the continual temperature time was $2 \mathrm{~h}$. The test was conducted when the specimens were cooled to room temperature in the furnace.

\subsection{Compressive Strength and Ultrasonic Pulse Velocity Determination}

The compressive strength of UHPC was determined based on the average value of three samples using the YAW-300C microcomputer-controlled automatic pressure testing machine, according to the Chinese standard GB/T 31387-2015.The ultrasonic pulse velocity of UHPC was determined by utilizing the average value of three samples through the NM-4A non-metallic ultrasonic detection analyzer, according to the standard CECS 02: 2005; three test points were taken for each surface of the test specimen. The degree of 
damage was obtained by Equation (1). In Equation (1), $V_{o}$ is the initial ultrasonic pulse velocity before exposure to high temperatures, $V_{t}$ is the ultrasonic pulse velocity after exposure to high temperatures, and $D$ is the degree of damage of the specimens $[37,38]$.

$$
D=1-\left(\frac{V_{t}}{V_{o}}\right)^{2}
$$

\subsection{Water Absorption and Chloride Diffusion Test}

Figure 2 shows the capillary water absorption test. The $100 \mathrm{~mm}$ cubic specimens were dried to a constant weight and sealed with wax on the side to ensure one-dimensional transportation of water. The surface slurry of the absorbing surface was ground away through an angle grinder so that it was entirely in contact with water and immersed in 3-5 $\mathrm{mm}$. The mass of water absorption was tested every once in a while, over a period of $72 \mathrm{~h}$.

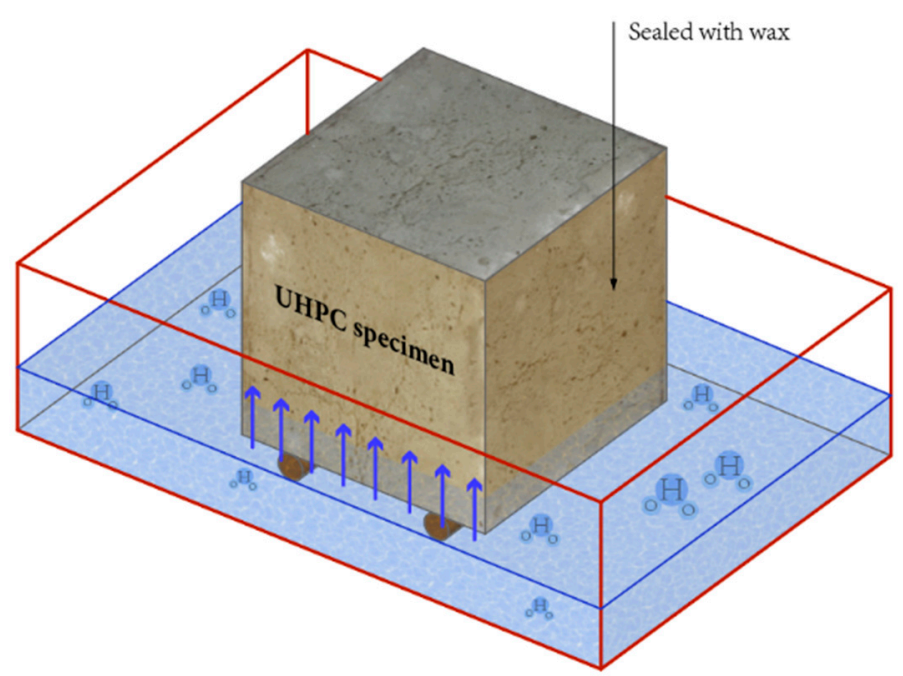

Figure 2. Diagram of the capillary water absorption test.

By ignoring the effect of gravity, the capillary water absorption coefficient can be calculated from Equations (2) and (3), where $\Delta W$ is the capillary water absorption per unit area $\left(\mathrm{g} \cdot \mathrm{m}^{-2}\right) ; m_{0}$ is the initial mass $(\mathrm{g}) ; m_{1}$ is the mass at the specified time point $(\mathrm{g}) ; S$ is the contact area with water $\left(\mathrm{m}^{2}\right) ; t$ is the water absorption time $(\mathrm{h}) ; A_{w}$ is the capillary water absorption coefficient $\left(\mathrm{g} \cdot \mathrm{m}^{-2} \cdot \mathrm{h}^{-1 / 2}\right)[39,40]$.

The capillary water absorption coefficient is generally obtained by fitting the water absorption curve of the initial $6 \mathrm{~h}$, and the higher the capillary water absorption coefficient, the higher the efficiency of water transportation. When considering the gravity factor, the relationship between capillary water absorption and time can be described by the exponential function, as shown in Equations (4) and (5), where $a$ and $b$ are the fitting coefficients, and $A_{i}=a \times b$ is the capillary water absorption coefficient with the change in the water absorption time [41,42].

$$
\begin{gathered}
\Delta W=\left(m_{1}-m_{0}\right) / S \\
\Delta W=A_{w} \sqrt{t} \\
\Delta W=a\left(1-e^{-b \sqrt{t}}\right) \\
A(t)=\frac{d \Delta W}{d \sqrt{t}}=A_{i} e^{-b \sqrt{t}}
\end{gathered}
$$


Chloride diffusivity is an important parameter used to assess the lifecycle and longterm durability of concrete. According to the Chinese standard GB/T 50082-2009 "Standard for test methods of long-term performance and durability of ordinary concrete", the rapid chloride migration method (RCM) was applied. The specimens were treated with sealing wax on the sides, and the experiments were conducted by a determination instrument, as shown in Figure 3. Finally, the chloride ion diffusion coefficient was estimated according to Equation (6), where $D_{R C M}$ is the non-stationary chloride ion mobility coefficient $\left(\times 10^{-12} \mathrm{~m}^{2} / \mathrm{s}\right), U$ is the absolute value of the used voltage $(\mathrm{V}), T$ is the average of the initial and final temperatures of the positive solution $\left({ }^{\circ} \mathrm{C}\right), L$ is the thickness of specimen $(\mathrm{mm})$, $X_{d}$ is the average value of chloride ion penetration depth $(\mathrm{mm}), t$ is the duration of the test (h) $[43,44]$.

$$
D_{R C M}=\frac{0.0239(273+T) \times L}{(U-2) \times t} \times\left(X_{d}-0.0238 \sqrt{\frac{(273+T) \times L \times X_{d}}{U-2}}\right)
$$
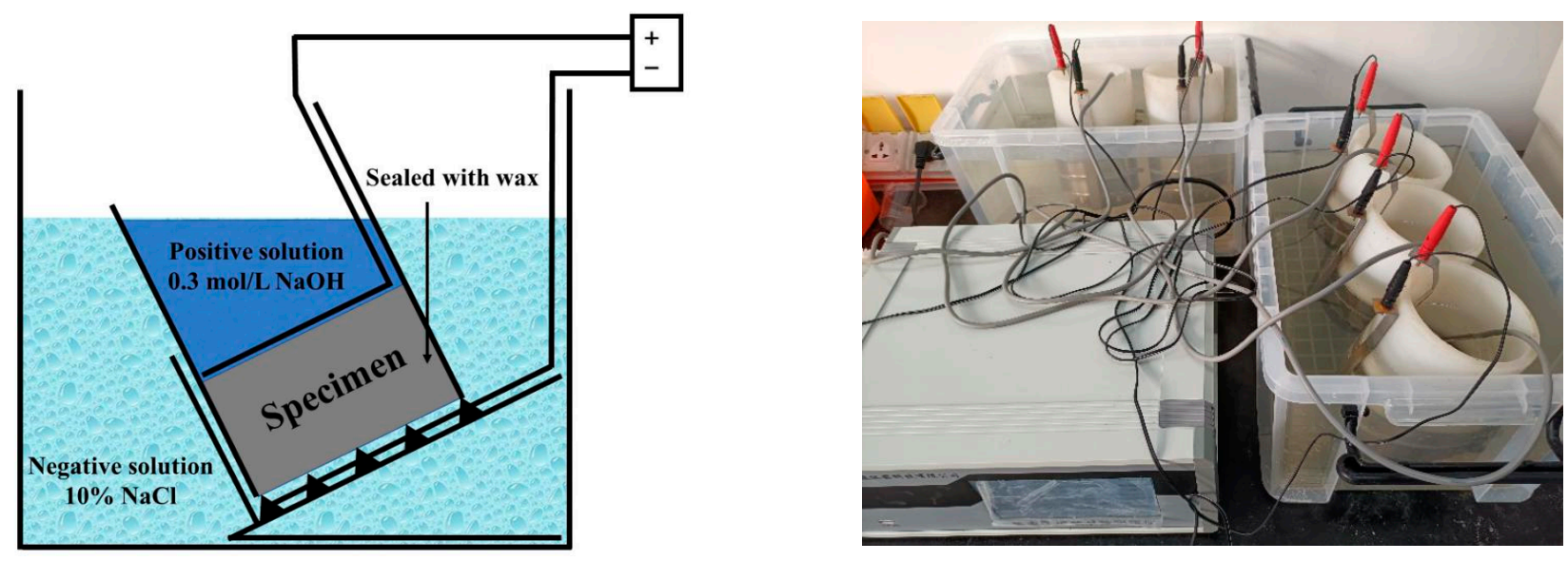

Figure 3. Schematic presentation and image of the RCM test.

\subsection{Microstructure Property Test}

X-ray Diffraction (XRD; Equipment: D8 Advance) was utilized to test the composition of the pastes after exposure to different temperatures and self-healing products in different environments, with angles ranging from $5-70^{\circ}$, along with the Fourier Transform Infrared Spectroscopy (FTIR; Equipment: Cary 610/670) for the self-healing products. The pore structure is closely related to the transport properties; hence, Mercury Intrusion Porosimetry (MIP; Equipment: AutoPore IV 9500) was utilized to test the pore structure of the pastes after exposure to elevated temperatures. Scanning Electronic Microscopy (SEM; Equipment: Gemini SEM 300) was utilized to observe the morphology of the fibers and the matrix of the pastes after exposure to elevated temperatures.

\section{Results and Discussion}

\subsection{Appearance and Weight Loss}

As the temperature increased, the appearance color gradually changes from cyan gray to reddish brown and light yellow, and the knocking sound became crisper. Some groups exploded, and the critical temperature was also different, as shown in Figure 4. The groups of PU and UN exploded above $400{ }^{\circ} \mathrm{C}$, while the degree of damage of the PU group was more serious, i.e., primarily small fragments. Above $800{ }^{\circ} \mathrm{C}$, steel fiber can effectively conduct heat and reduce the internal thermal stress difference, and the space left by synthetic fibers after exposure to high temperatures was conducive to the release of vapor pressure, and the UP, SP, and SN groups remained intact. In the case of the UN and SN groups, this occurred mainly because the PAN fiber cannot leave enough space to 
release pressure after experiencing high temperatures, and the steel fiber dispersed in the interior can not only transfer heat effectively, but also form a relatively stable framework to restrict the specimen $[45,46]$.

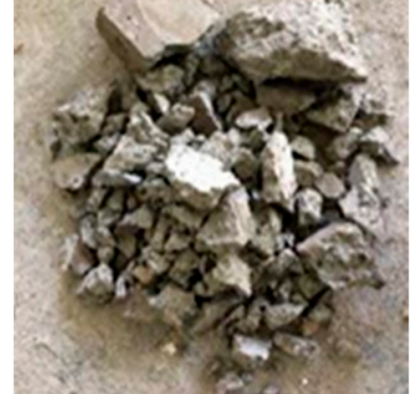

(a) PU-400 ${ }^{\circ} \mathrm{C}$

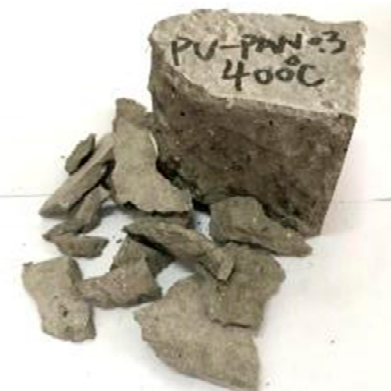

(b) $\mathrm{UN}-400{ }^{\circ} \mathrm{C}$

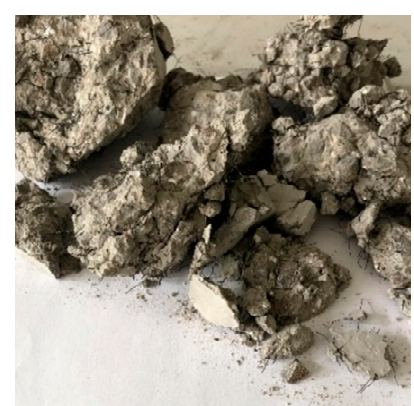

(c) $\mathrm{US}-600{ }^{\circ} \mathrm{C}$

Figure 4 . The bursting specimens after exposure to high temperatures.

Figure 5 shows the surface condition observed by the stereomicroscope. The number of cracks increased with the increase in temperature. The cracking phenomenon appeared on the surface above $800{ }^{\circ} \mathrm{C}$, with broad and fine cracks jaggedly spread all over. The crack width also increased. Taking the $200{ }^{\circ} \mathrm{C}$ group as the reference group, the crack width at $400{ }^{\circ} \mathrm{C}, 600{ }^{\circ} \mathrm{C}$, and $800{ }^{\circ} \mathrm{C}$ was 2 times, 3 times, and 4 times, which increased in a multiplicative relationship. According to the principle of thermal stress [20,25], concrete itself is a polymorphic and non-homogeneous composite material. The heat transfer and thermal conductivity of the internal materials differ from each other, resulting in a more obvious temperature gradient after being subjected to high temperatures. The thermal expansion trend between the materials was not consistent, which in turn generated thermal stress. When it exceeds the tolerance range of concrete itself, it cannot resist the change in temperature stress, and various internal parts will expand, which will eventually contribute to the generation and development of cracks. The admixture of steel fiber and PP fiber formed a three-dimensional chaotic distribution of the internal space structure, reducing the phenomenon of partial stress concentration and delaying the appearance and expansion of cracks. The steel fiber with good thermal conductivity can transfer and disperse heat faster and more evenly, so the specimen can withstand a higher temperature before cracking or bursting.
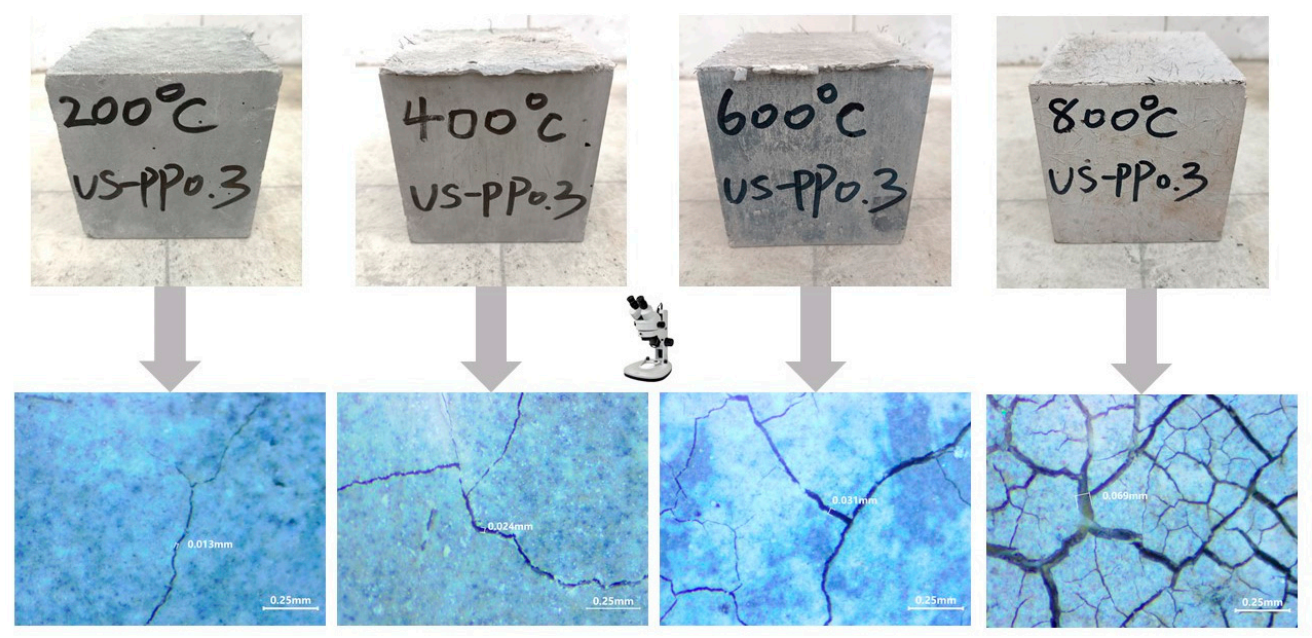

Figure 5. Surface crack conditions after exposure to high temperatures.

After exposure to elevated temperatures, the concrete undergoes specific changes in its internal material composition and microstructure, resulting in varying degrees of 
changes in its quality [47]. The specimens were weighed after cooling to room temperature. The variation curves between the mass loss rate of UHPC and temperature were measured for each group, as shown in Figure 6. The results were consistent with those of Sanchayan et al. [47] and Gong et al. [48]. Above $200{ }^{\circ} \mathrm{C}$, the mass loss was not significant, with an average loss rate of $1.04 \%$, which is less than $2 \%$, with the lowest loss rate of $0.41 \%$ for the US and the largest for the single-doped synthetic fibers (UN and UP), which were $1.31 \%$ and $1.69 \%$, respectively. The main mass loss in this temperature section is due to the evaporation of moisture, along with the melting or softening of synthetic fibers. Above $400{ }^{\circ} \mathrm{C}$, the mass loss was pronounced, with an average loss rate of $5.33 \%$; the lowest was $3.62 \%$ for the US, and the highest was $6.44 \%$ for the UP. This occurred because the combined water in hydrated products such as C-S-H gels starts to decompose in sequence, which makes more water escape from the interior. At the same time, the softened or molten synthetic fibers also undergo melting and evaporation. Above $600{ }^{\circ} \mathrm{C}$ and $800{ }^{\circ} \mathrm{C}$, the mass loss continued to increase with an average loss rate of $7.54 \%$ and $9.04 \%$, respectively, and the UP remained the highest. The loss within this temperature range is mainly attributable to the internal $\mathrm{CaCO}_{3}, \mathrm{Ca}(\mathrm{OH})_{2}$ and other materials that continue to decompose, along with the chemically bound water that is continuously lost.

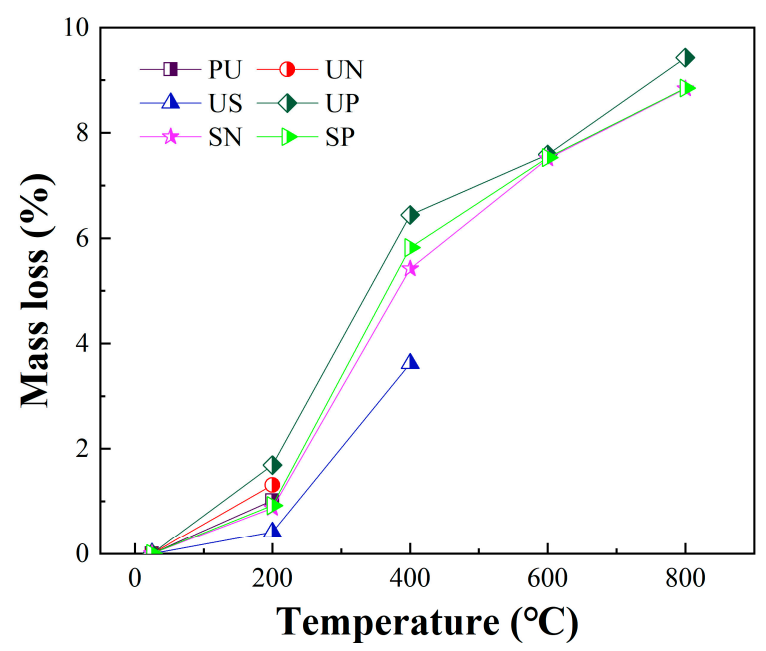

Figure 6. Mass loss after exposure to high temperatures.

\subsection{Mechanical Properties}

During the test, the PU and the single-doped synthetic fiber groups (UN and UP) both split into pieces and scattered everywhere after a loud burst sound, with more apparent brittle damage; the UN and UP groups were less broken than the PU due to the admixture of synthetic fibers. Cracks occurred on the surface after the damage among the groups containing steel fibers (US, SN, and SP), maintaining the integrity much better. The mechanical properties (compressive strength and ultrasonic pulse velocity) of UHPC after exposure to high temperatures are shown in Figure 7. As can be seen from Figure 7a, except for the PU group, which decreased after exposure to high temperatures, the rest of the groups showed a change in the pattern, of increasing and then decreasing, where a turning occurred at $400{ }^{\circ} \mathrm{C}$ with an increase ranging from 5-10 MPa. The compressive strength above $200{ }^{\circ} \mathrm{C}, 400{ }^{\circ} \mathrm{C}, 600{ }^{\circ} \mathrm{C}$, and $800{ }^{\circ} \mathrm{C}$ was approximately $105 \%, 115 \%$, $75 \%$, and $30 \%$ respectively, with 25 as the reference. The test results are in agreement with the conclusions of Yang et al. [14] and Sanchayan et al. [47]. This is because many internal mineral admixtures (silica fume and fly ash) that have not hydrated yet and escaping water co-exist in the high temperatures and humidity interior space, stimulating and promoting cement hydration and volcanic ash reaction, correspondingly increasing the compressive strength [14]. Above $400{ }^{\circ} \mathrm{C}$, most synthetic fibers had shrunk or decomposed, and the internal cracks and pores increased considerably. The internal damage generated by high 
temperatures and the deterioration caused by the melting of synthetic fibers dominated.

Thus, only less than $40 \%$ of the strength remained above $800{ }^{\circ} \mathrm{C}$.

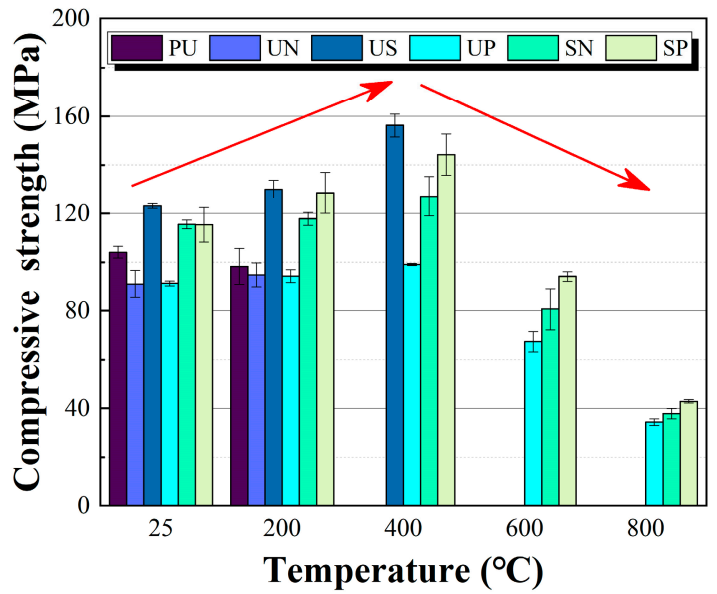

(a) Compressive strength

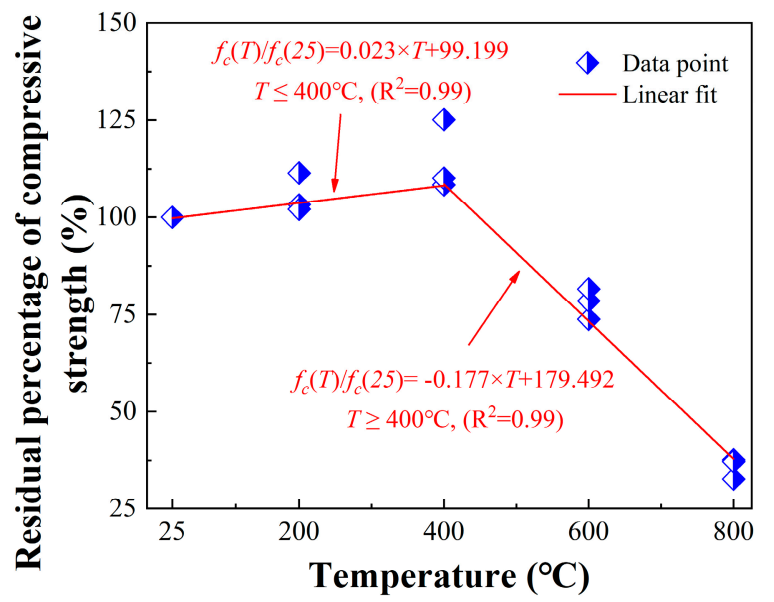

(c) Residual compressive strength

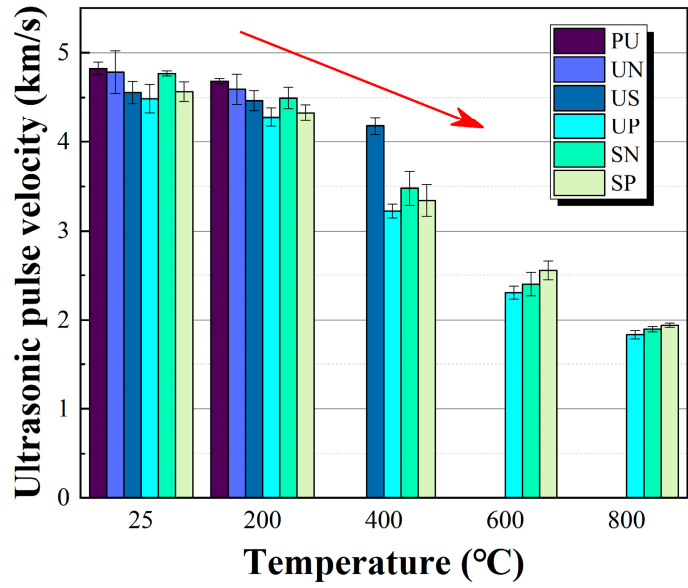

(b) Ultrasonic pulse velocity

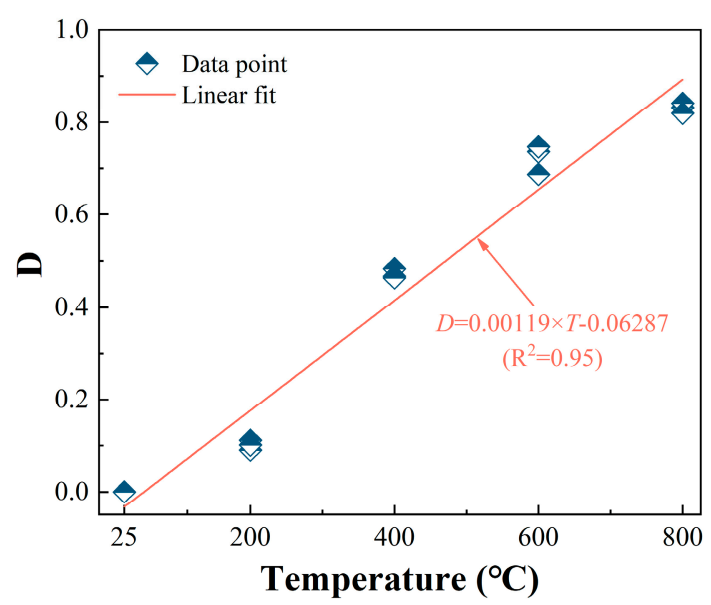

(d) Degree of damage

Figure 7. Mechanical properties of UHPC after exposure to high temperatures.

A variety of factors can affect the propagation of ultrasonic pulse velocity (Figure $7 \mathrm{~b}$ ), and the change in the pattern was a decrease with increasing temperatures. The results are similar to those of Gong et al. [48]. Taking 25 as the reference, the ultrasonic pulse velocity above $200{ }^{\circ} \mathrm{C}, 400{ }^{\circ} \mathrm{C}, 600{ }^{\circ} \mathrm{C}$, and $800{ }^{\circ} \mathrm{C}$ was about $95 \%, 75 \%, 55 \%$, and $40 \%$, respectively. The main reason is that with increases in the internal evaporated water, the decomposed material and micro-cracks, pores, etc., also increased when the temperature increased. There was a large number of internal air spaces and other media, leading to a decrease in the length of ultrasonic vibrations in the concrete and an increase in the distance of ultrasonic vibrations in the air [48]. The propagation velocity of ultrasonic pulses in concrete (about $4 \mathrm{~km} / \mathrm{s}$ ) is obviously higher than that in the air (about $0.34 \mathrm{~km} / \mathrm{s}$ ), and the velocity of ultrasonic pulses gradually decreased with the extension of the air gap.

Figure $7 \mathrm{c}$ shows the residual percentage of compressive strength after exposure to different temperatures, with the compressive strength of $25^{\circ} \mathrm{C}$ as the reference. It also shows the related equations in order to predict the compressive strength after exposure to elevated temperatures. In equations, $T$ is the elevated temperature, $f_{c}(T)$ is the compressive strength after exposure to elevated temperatures, and $f_{c}(T)$ is the compressive strength at $25^{\circ} \mathrm{C}$.

When the ultrasonic waves spread through the cracks, the measured velocity will be decreased compared to the velocity without cracks. Therefore, the ultrasonic pulse velocity 
of concrete can reflect the performance and its internal conditions. The measured ultrasonic pulse velocity can be converted into the degree of damage by Equation (1). From the data of the groups without bursting (UP/SP/SN) and Equation (1), Figure $7 \mathrm{~d}$ further shows the relationship between the damage degree and high temperature, and there was a well-fitted linear relationship between them. The degree of damage above $25^{\circ} \mathrm{C}, 200{ }^{\circ} \mathrm{C}, 400{ }^{\circ} \mathrm{C}$, $600{ }^{\circ} \mathrm{C}$, and $800{ }^{\circ} \mathrm{C}$ was about $0,0.1,0.5,0.7$, and 0.8 , respectively. Figure $7 \mathrm{~d}$ also shows a detailed equation, where $D$ is the damage degree, and $T$ is the elevated temperature.

\subsection{Transport Properties}

The groups without bursting in the whole process were selected for the capillary water absorption test. Because of the specification requirements, steel fiber-containing specimens cannot be used for the RCM test. Therefore, the UP group was selected for the RCM test, and the results are shown in Figure 8. The change trend is similar to that presented by Poon et al. [29] and Nadeem et al. [30]. Since UHPC is very dense and it is difficult for external substances to invade the material, the phenomenon of chloride ion migration could hardly be detected inside at room temperature during the experiment, so the result was set to 0 . With the increase in temperature, the migration coefficient also gradually increased, and it began to deteriorate obviously after $400{ }^{\circ} \mathrm{C}$. Due to the capacity to reflect the evolution of the pore structure, the two were in good agreement based on a comparison with the ultrasonic wave velocity. UHPC has low porosity, a dense structure, and poor connectivity of pores. The steam pressure caused by high temperatures cannot be effectively released, which leads to energy accumulation and considerable pore pressure, and finally makes the pore structure more severely and significantly damaged.

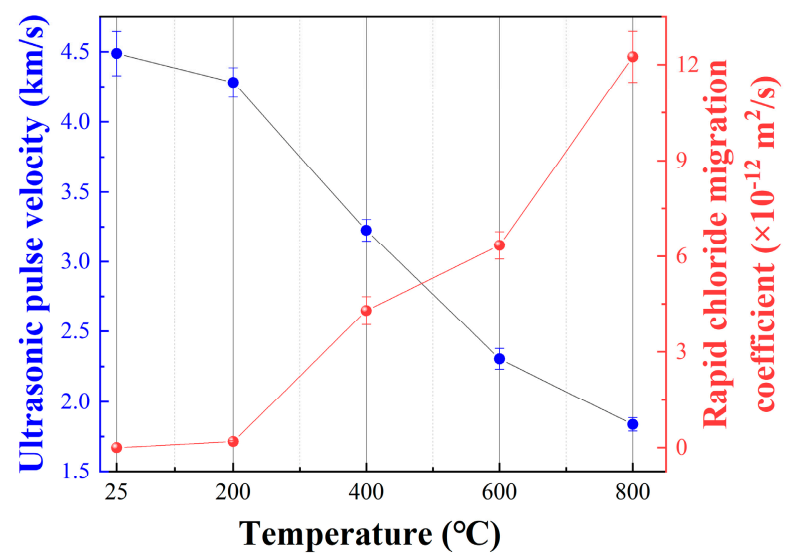

Figure 8. Results of RCM after exposure to high temperatures.

Figure 9 shows the capillary water absorption curve after exposure to elevated temperatures. When the target temperature increased, the water absorption per unit area increased, and the higher the temperature, the sooner it tended to level off. The threshold temperature was $400{ }^{\circ} \mathrm{C}$, above which the water absorption substantially increased. Taking the UP as an example, with $25^{\circ} \mathrm{C}$ as the standard, after $72 \mathrm{~h}$ of water absorption, the values for $200{ }^{\circ} \mathrm{C}, 400{ }^{\circ} \mathrm{C}, 600{ }^{\circ} \mathrm{C}$, and $800{ }^{\circ} \mathrm{C}$ were $1.31,14.78,90.04$, and 117.73 times. Table 4 shows the variation in the initial capillary water absorption coefficient. Taking the UP group as an example, with $25^{\circ} \mathrm{C}$ as the reference, the initial capillary water absorption coefficients were $1.70,15.85,102.76$, and 299.14 times for $200^{\circ} \mathrm{C}, 400{ }^{\circ} \mathrm{C}, 600{ }^{\circ} \mathrm{C}$, and $800{ }^{\circ} \mathrm{C}$, respectively. The change trend is consistent with that presented by Sideris et al. [31].

Based on Equation (5) and an exploration of the capillary water absorption coefficientabsorption time curve after exposure to high temperatures by an exponential function, the general trend was similar for all groups (Figure 10). This occurred because [42,49] the early water absorption of concrete mainly depends on the capillary suction. When the concrete specimens are in contact with moisture initially, the water invades rapidly, 
and later the rate slows down. It was recognized that the invaded moisture increased the internal humidity of concrete, gradually filling the internal pores. The capillary suction force also decreased accordingly, showing a trend of a flat curve. Above $800{ }^{\circ} \mathrm{C}$, due to the presence of a great deal of internal deterioration damage formed by pores and cracks, the early water invasion increased dramatically; at the same time, the curve varied more rapidly and tended to decline and become moderate.

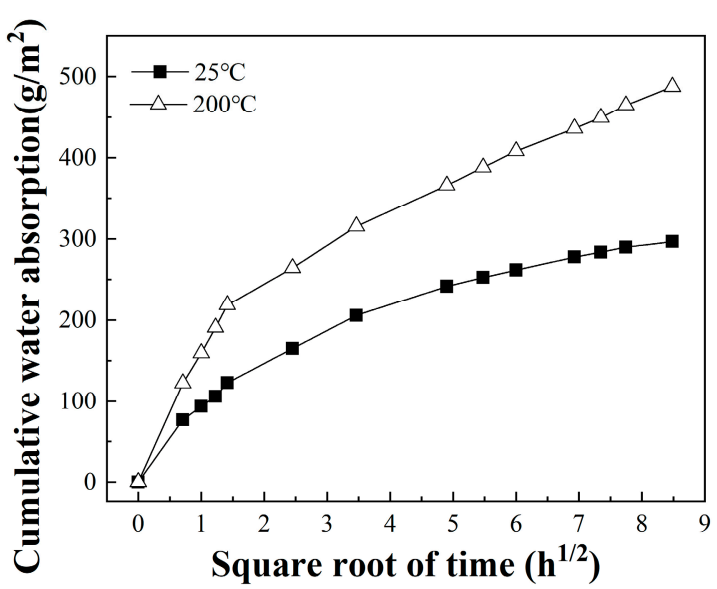

(a) PU

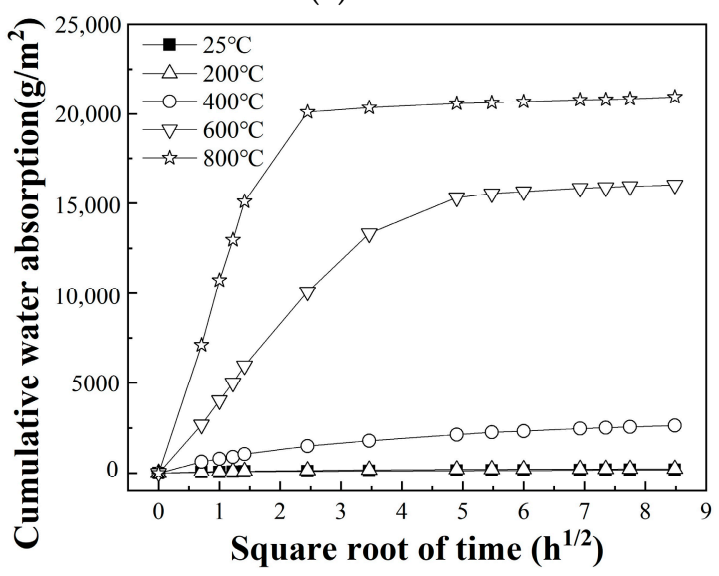

(c) UP

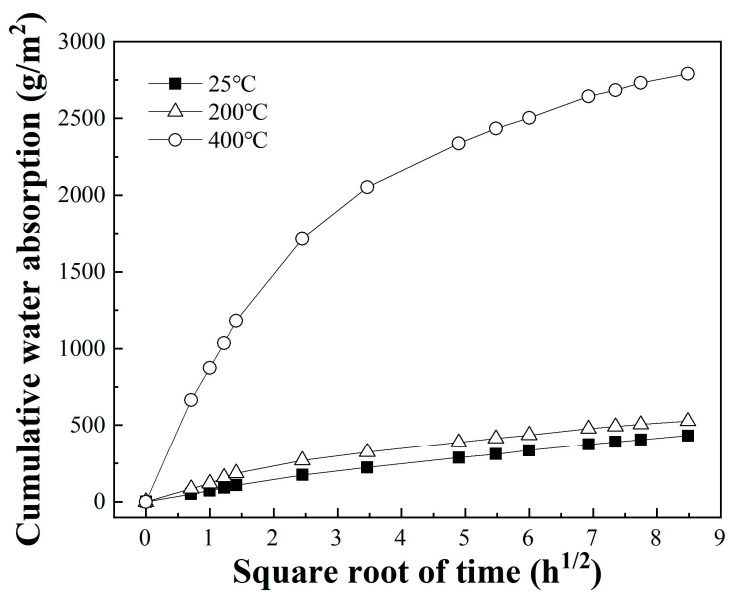

(b) US

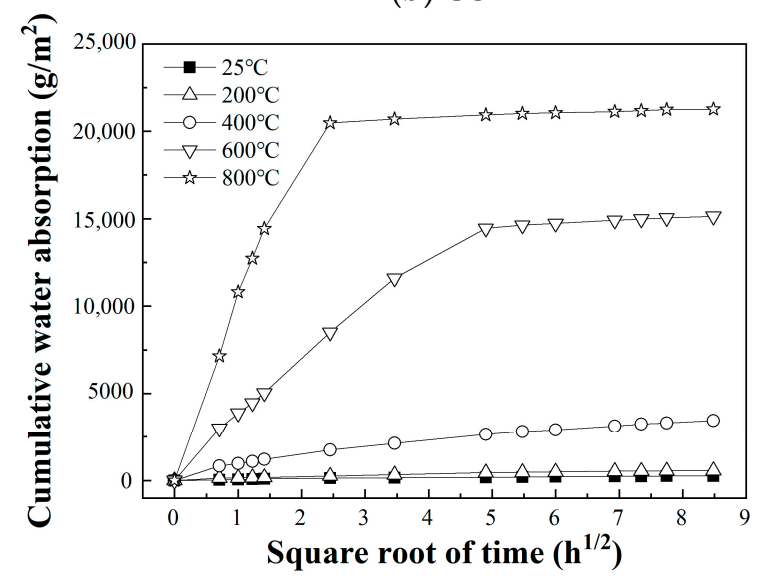

(d) SP

Figure 9. Capillary water absorption curves after exposure to high temperatures.

Table 4. Initial capillary water absorption coefficients after exposure to high temperatures.

\begin{tabular}{ccccc}
\hline $\boldsymbol{T}\left({ }^{\circ} \mathbf{C}\right)$ & PU & US & UP & SP \\
\hline 25 & 95.89 & 77.87 & 55.92 & 64.30 \\
200 & 168.17 & 128.81 & 95.20 & 146.48 \\
400 & - & 1040.40 & 880.87 & 969.67 \\
600 & - & - & 5367.46 & 7364.33 \\
800 & - & - & $16,868.97$ & $16,337.68$ \\
\hline
\end{tabular}

The changes in the water absorption curve and water absorption coefficient were mainly caused by the internal microstructure evolution. After exposure to high temperatures, the escape of free and bound water, the decomposition of hydration products, and the coarsening of pores would lead to an increase in porosity. The difference in the shrinkage or expansion between components due to thermal conductivity will also cause the appearance and development of micro-cracks and pores, which will lead to the enhancement of capillary action, making it much easier and faster for moisture to penetrate. 


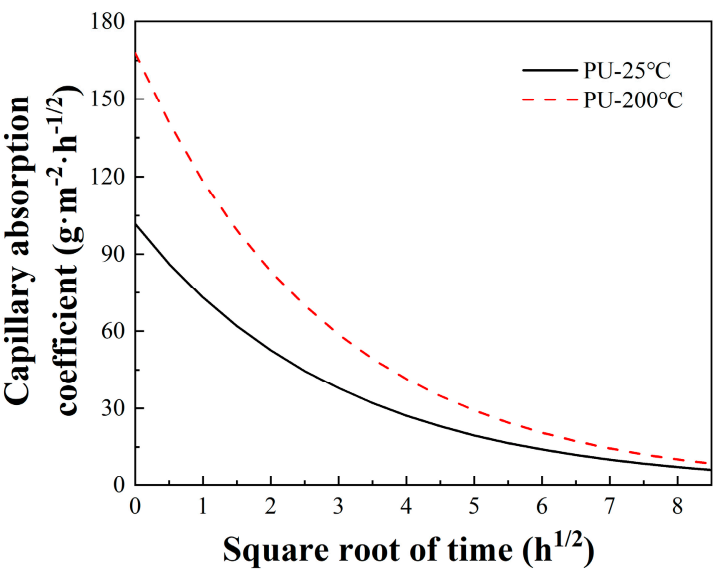

(a) PU

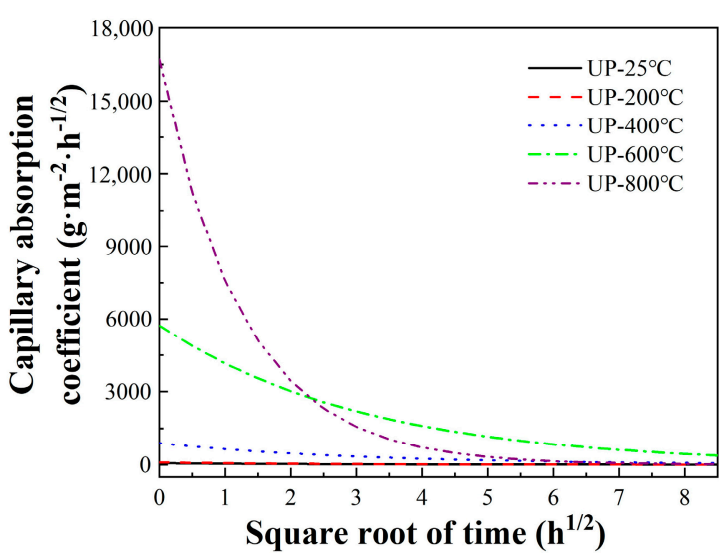

(c) UP

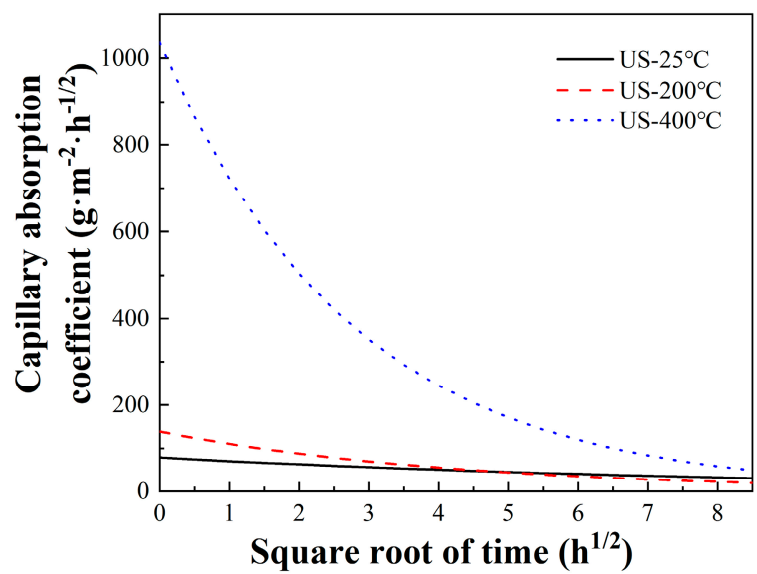

(b) US

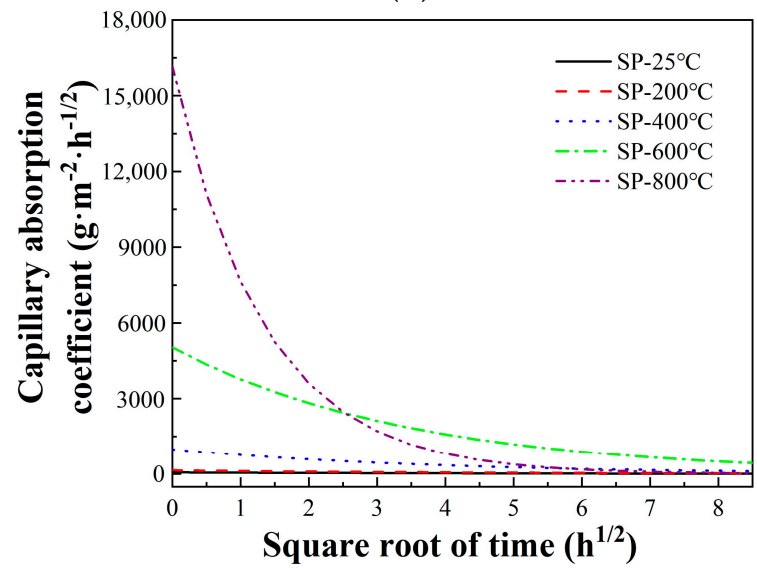

(d) SP

Figure 10. Capillary water absorption coefficient curves after exposure to high temperatures.

\subsection{Microstructure Properties}

\subsubsection{XRD}

The variation patterns of the main components were analyzed by XRD (Figure 11). Among them, the peaks of $\mathrm{CaCO}_{3}$ (around $2 \theta=29.4^{\circ}$ ), $\mathrm{C}_{2} S \& \mathrm{C}_{3} \mathrm{~S}$ (around $2 \theta=32.5^{\circ}$ ), and $\mathrm{Ca}(\mathrm{OH})_{2}\left(\right.$ around $\left.2 \theta=62.4^{\circ}\right)$ varied greatly. With the increase in temperature, the peak value of $\mathrm{CaCO}_{3}$ first increased and then decreased, the peak value of $\mathrm{C}_{2} \mathrm{~S}$ and $\mathrm{C}_{3} \mathrm{~S}$ first decreased and then increased, and the peak value of $\mathrm{Ca}(\mathrm{OH})_{2}$ gradually decreased.

The more intense the carbonation reaction in the specimen after exposure to high temperatures [50], the more pronounced the peaks of $\mathrm{CaCO}_{3}$. The decomposition of $\mathrm{CaCO}_{3}$ occurred approximately at $650{ }^{\circ} \mathrm{C}$, so its peaks showed a sudden drop above $800{ }^{\circ} \mathrm{C}$. A suitable high temperature (less than $400^{\circ} \mathrm{C}$ ) can stimulate and increase the volcanic ash activity of some mineral admixtures (fly ash and silica fume), which can react with $\mathrm{Ca}(\mathrm{OH})_{2}$ faster, more frequently, and more comprehensively. When the volcanic ash reaction rate exceeds the cement hydration reaction rate, the consumption of $\mathrm{Ca}(\mathrm{OH})_{2}$ will be higher. The internal pores are filled more fully, promoting the densification of the internal structure, and thus contributing to a strong improvement in a certain period. The decomposition of $\mathrm{Ca}(\mathrm{OH})_{2}$ was also basically completed at about $500{ }^{\circ} \mathrm{C}$, and then gradually decreased. Above $800{ }^{\circ} \mathrm{C}$, the decomposition of the C-S-H gels was significant, resulting in a marked broadening and enhancement of the peaks of $C_{2} S$ and $C_{3} S$. 


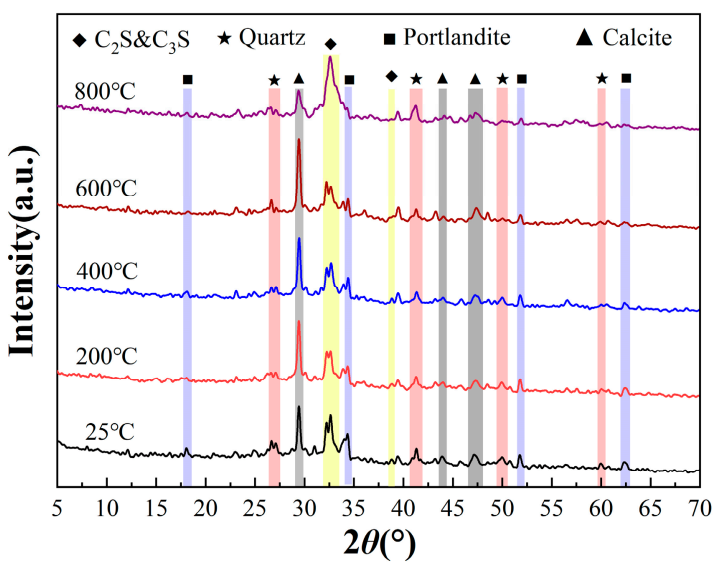

(a) Total

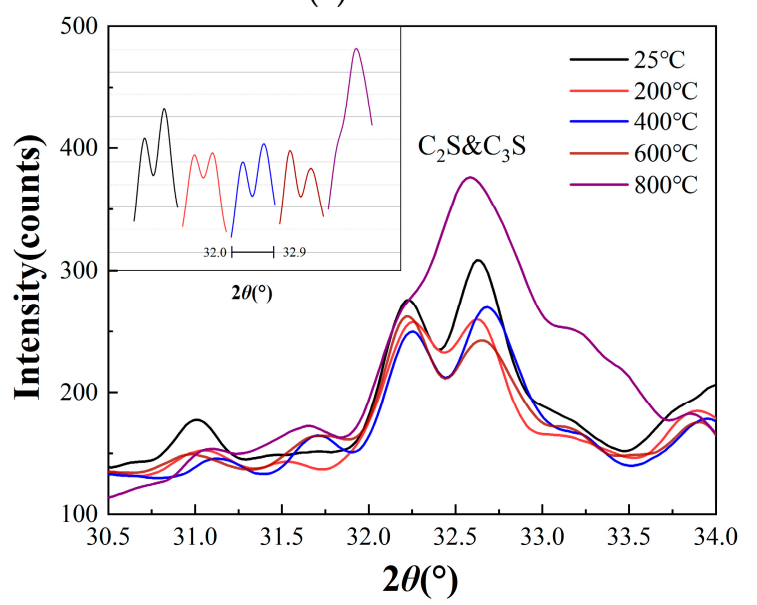

(c) $\mathrm{C}_{2} \mathrm{~S} \& \mathrm{C}_{3} \mathrm{~S}$

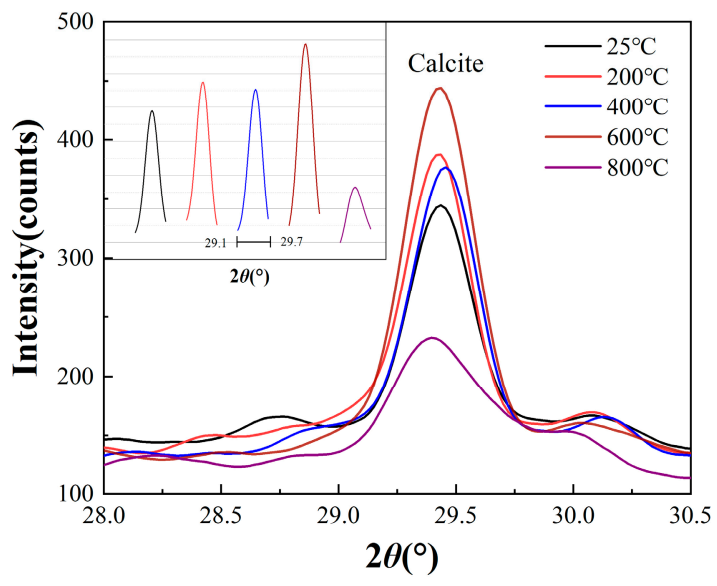

(b) Calcite

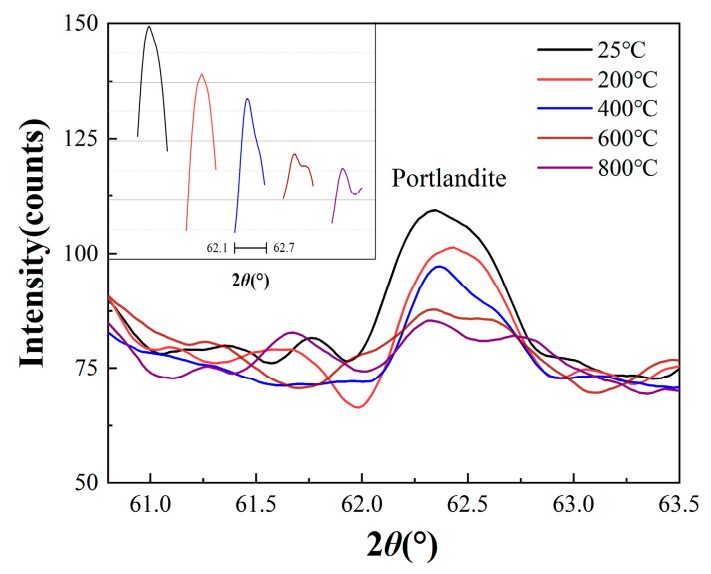

(d) Portlandite

Figure 11. Phase composition of UHPC after exposure to high temperatures.

\subsubsection{MIP}

It is well known that the macroscopic mechanical properties of materials are often closely related to the microstructure. The macroscopic phenomenon of the final destabilization and damage of concrete materials is the externalization of its internal micro-cracks that form, develop, and expand to form visible cracks. Therefore, the perceptible results of substantial damage are determined by the internal micro-damage evolution. Consequently, there is an inevitable link between the deterioration of macroscopic mechanical properties after exposure to high temperatures and microscopic damage evolution.

According to the MIP test data (Figure 12), the high temperature significantly affected the pore structure, the overall porosity, and various pore parameters, which showed different degrees of increase. Compared to $200{ }^{\circ} \mathrm{C}$, the increase in porosity reached $308.65 \%$, and the increase in the average pore size was $422.75 \%$ at $800{ }^{\circ} \mathrm{C}$. As seen from Figure $12 \mathrm{a}$, the trend of the cumulative curves at different temperatures was similar to that presented by Missemer et al. [5]. The critical pore size where the amount of incoming mercury starts to increase substantially was also related to the temperature, with the essential pore sizes of $26.29 \mathrm{~nm}, 32.40 \mathrm{~nm}, 50.39 \mathrm{~nm}$, and $349.01 \mathrm{~nm}$ for $200{ }^{\circ} \mathrm{C}, 400{ }^{\circ} \mathrm{C}, 600{ }^{\circ} \mathrm{C}$, and $800{ }^{\circ} \mathrm{C}$, respectively. As shown in Figure 12b, the curve shifted to the right as a whole and the most probable pore diameter increased. 


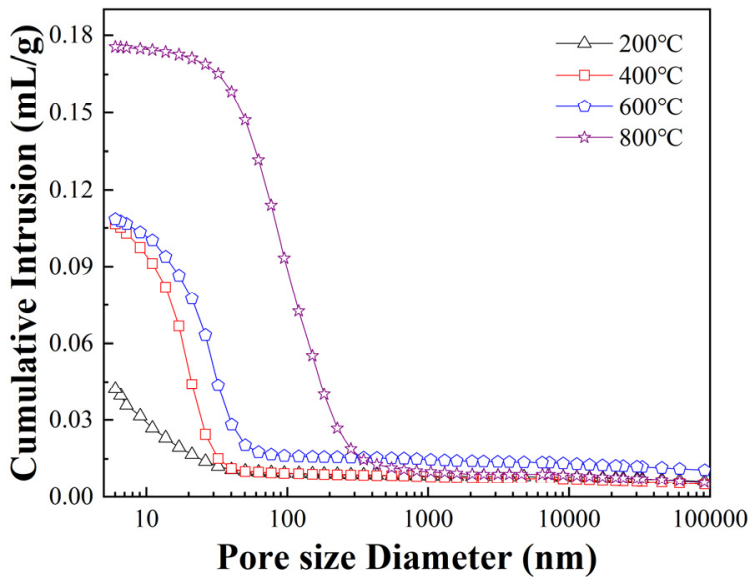

(a) Cumulative intrusion

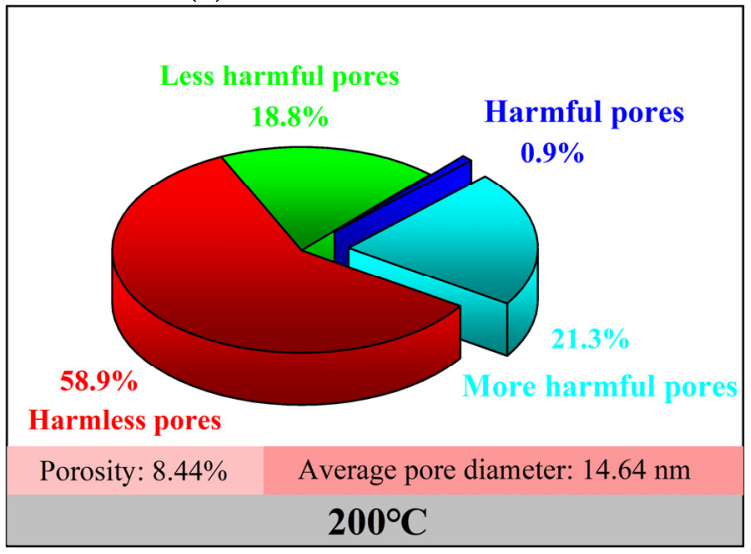

(c) Parameters of UHPC above $200{ }^{\circ} \mathrm{C}$

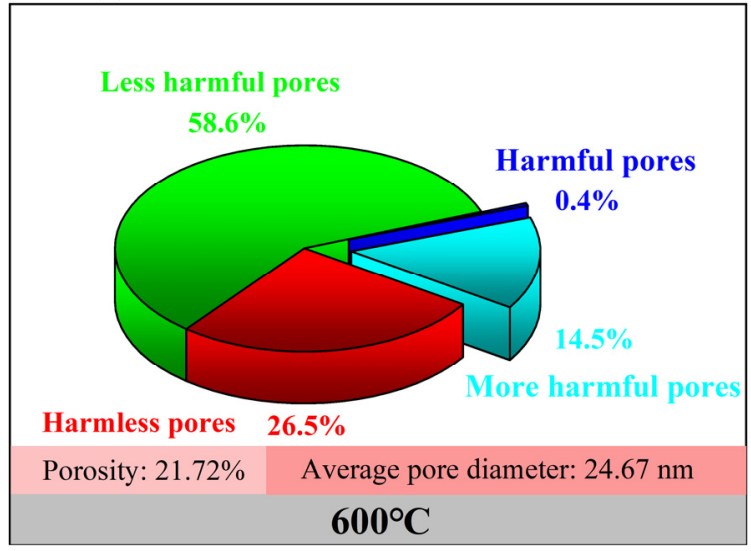

(e) Parameters of UHPC after $600{ }^{\circ} \mathrm{C}$

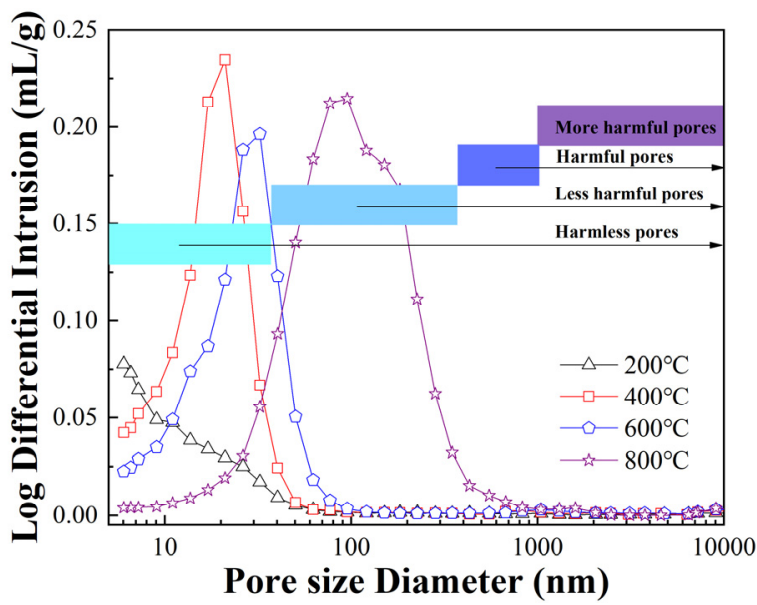

(b) Log differential intrusion

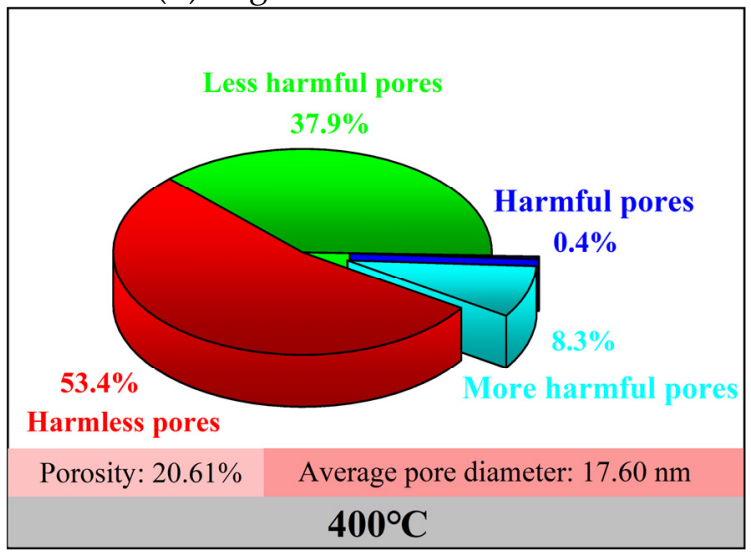

(d) Parameters of UHPC above $400^{\circ} \mathrm{C}$

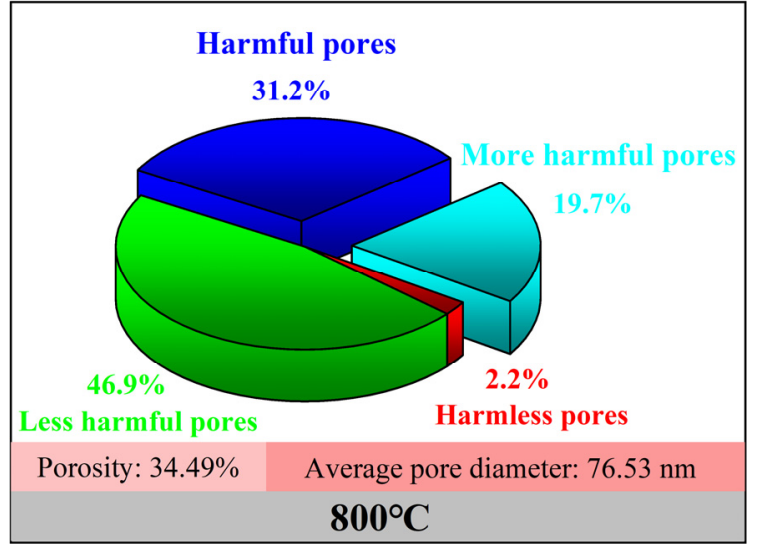

(f) Parameters of UHPC above $800^{\circ} \mathrm{C}$

Figure 12. Pore structure of UHPC after exposure to high temperatures.

The pore sizes were classified as follows: pore sizes $<20 \mathrm{~nm}$ as harmless pores; pore sizes 20-100 nm as less harmful pores; pore sizes 100-200 nm as harmful pores; and pore sizes $>200 \mathrm{~nm}$ as more harmful pores. Compared to $200^{\circ} \mathrm{C}$, when the temperature was $400{ }^{\circ} \mathrm{C}$, the rate of multi-harmful pores decreased by $13.0 \%$ and the percentage of lessharmful pores increased by $19.1 \%$. The phenomenon indicates that during the heating process from $200{ }^{\circ} \mathrm{C}$ to $400{ }^{\circ} \mathrm{C}$, the appropriate temperature was conducive to the hydration reaction of the mineral admixture. The generated hydration products further filled the larger internal pores and disintegrated the large pores into small ones, effectively optimizing and improving the pore structure system. 
During the heating process from $400{ }^{\circ} \mathrm{C}$ to $600{ }^{\circ} \mathrm{C}$, the percentage of harmless pores decreased by $26.9 \%$, and the rate of less harmful pores increased by $20.7 \%$. This is because [51] the large amount of hydrated material produced in a short time in the early temperature section cannot be distributed in an orderly manner. The high temperature can also accelerate the rate of water loss. Further, the hydration of cement particles is insufficient in the later stage; shrinkage cracks appear and develop in a dry and hot environment, in addition to large-scale decomposition of $\mathrm{Ca}(\mathrm{OH})_{2}$. The superposition of various factors results in continuous coarsening of the pores.

During the heating process from $600{ }^{\circ} \mathrm{C}$ to $800{ }^{\circ} \mathrm{C}$, the percentage of harmless pores decreased by $24.3 \%$ and the rate of harmful pores increased by $30.8 \%$, which is due to the continuation of the various types of influential behaviors mentioned above. Moreover, the decomposition of crystals such as C-S- $\mathrm{H}$ gels and $\mathrm{CaCO}_{3}$ was also completed in large quantities. Eventually, significant destruction of the pore structure system occurred [52].

\subsubsection{SEM}

Figure 13 shows the SEM images of the cement matrix after exposure to elevated temperatures. It was found that the presence of fiber could still be observed above $200{ }^{\circ} \mathrm{C}$, and the surface of the fiber tended to separate. The root of the fiber bonding to the matrix also tended to detach. Above $400{ }^{\circ} \mathrm{C}$, the pore channels left by the melting of PP fiber can be seen. Cracks and pores appeared on the surface of the matrix near the pores and gradually loosened. PP fibers exist in concrete with a three-dimensional spatial chaotic distribution, and the staggering pore channels left after exposure to high temperatures will aggravate the void defects of the internal structure, although they provide an escape exit for the internal moisture to inhibit the burst.

Strip-shaped plate-like crystals were observed in the matrix at $200{ }^{\circ} \mathrm{C}$, which, according to the literature [53], is Tobermorite with a lower calcium-to-silicon ratio and higher hardness. The coexistence of dense and continuous C-S-H gels with the Tobermorite formed by transformation after exposure to high temperatures was macroscopically manifested as an enhancement of the compressive strength.

The matrix was severely damaged above $800{ }^{\circ} \mathrm{C}$, with pores and cracks available everywhere. The external structure of C-S-H gels was loose and similar to a honeycomb. Most of the surface or internal water escaped and left pits and holes, leading to a sudden deterioration of compressive strength, ultrasonic pulse velocity, and capillary water absorption above $800{ }^{\circ} \mathrm{C}$.

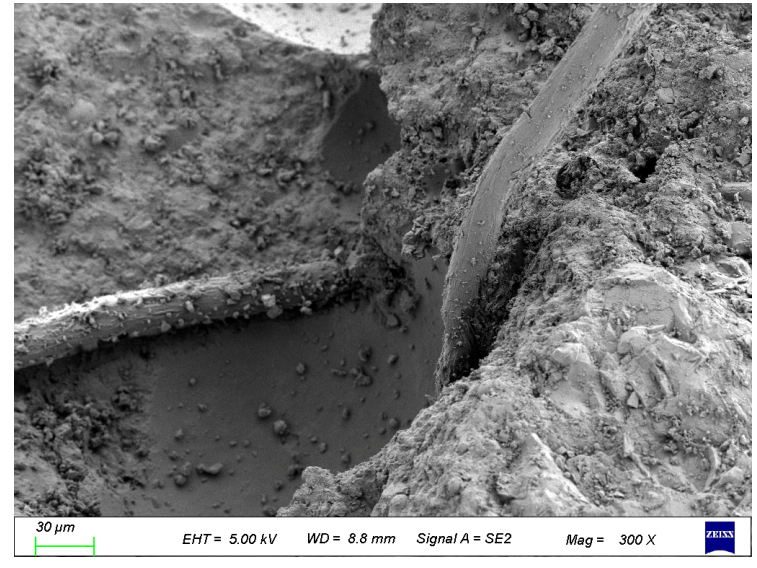

(a) The fiber above $25^{\circ} \mathrm{C}$

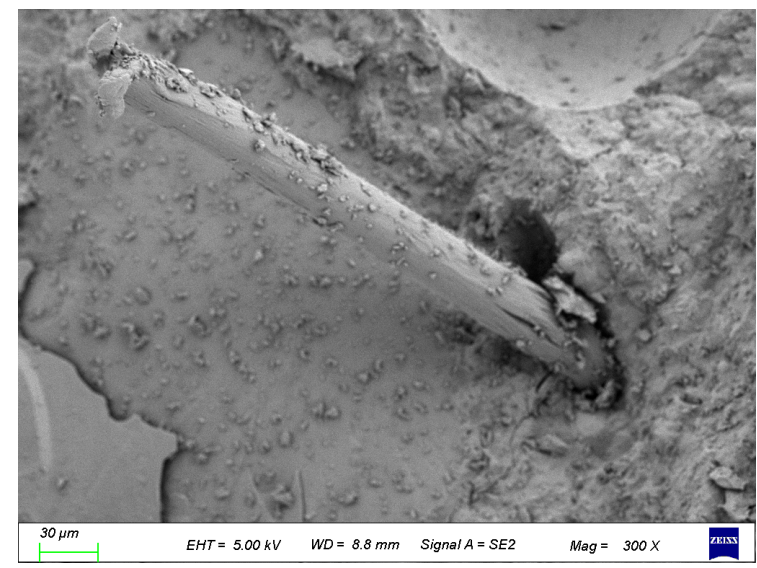

(b) The fiber above $200{ }^{\circ} \mathrm{C}$

Figure 13. Cont. 


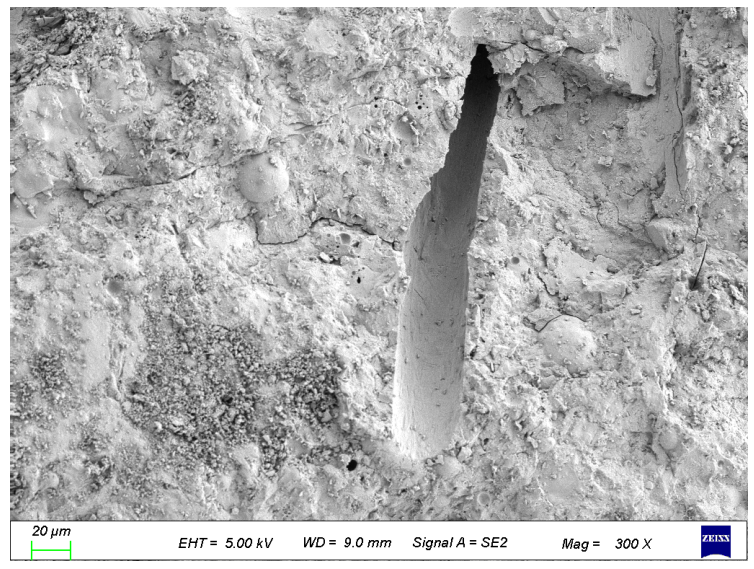

(c) The fiber above $400{ }^{\circ} \mathrm{C}$

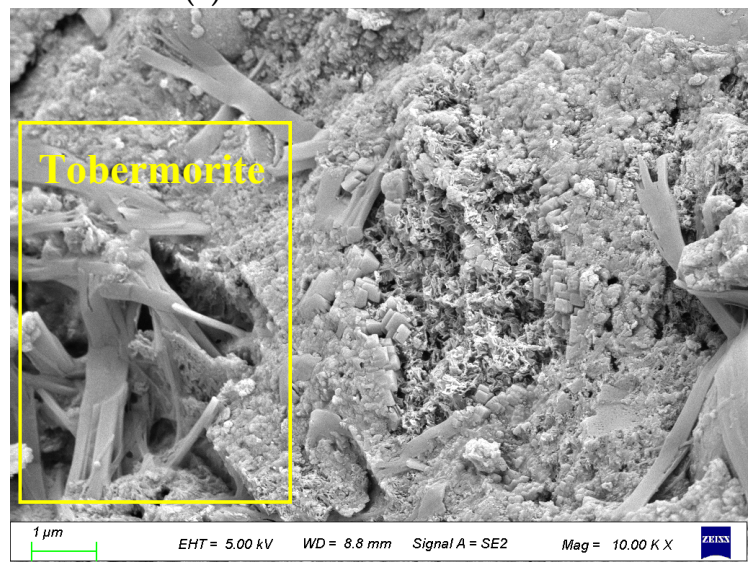

(e) The matrix above $200{ }^{\circ} \mathrm{C}$

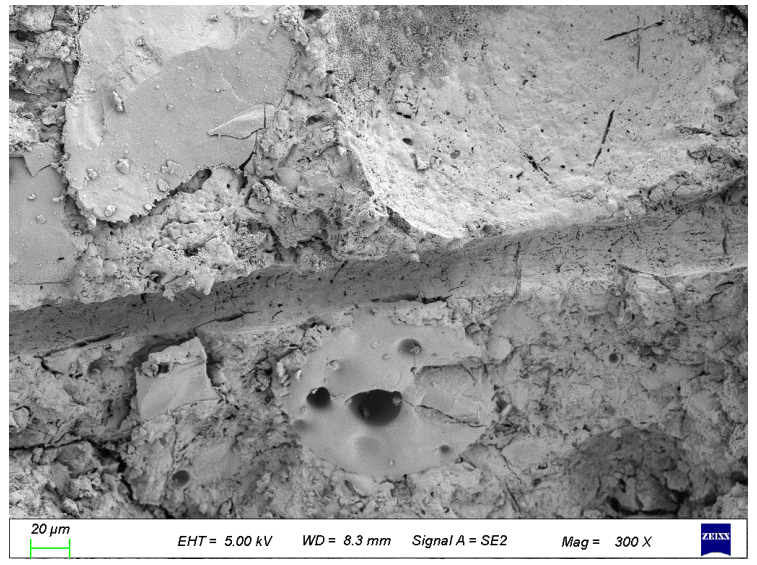

(d) The fiber above $800^{\circ} \mathrm{C}$

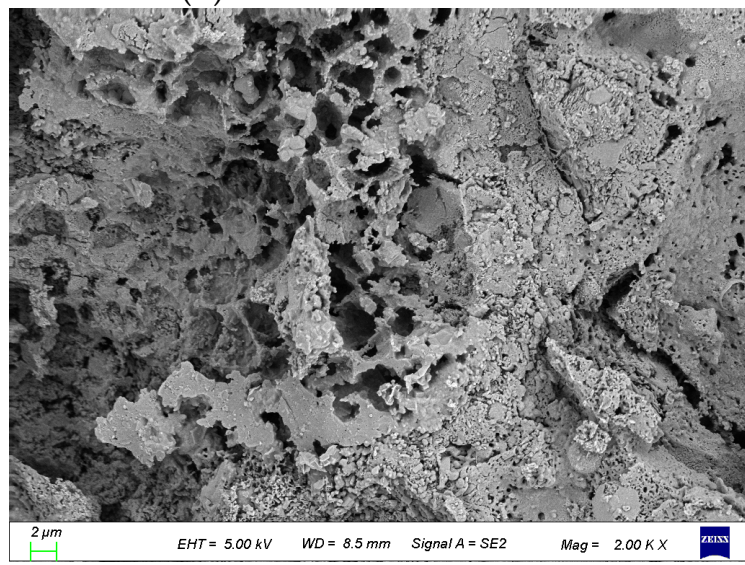

(f) The matrix above $800^{\circ} \mathrm{C}$

Figure 13. SEM images of UHPC after exposure to high temperatures.

\subsection{Property Enhancement and Improvement \\ 3.5.1. Mechanical Properties}

According to the high-temperature performance test, $400{ }^{\circ} \mathrm{C}$ was the most crucial temperature point, and the change trend of each group was similar. Therefore, for the self-healing test after exposure to high temperatures, the UP groups above $200{ }^{\circ} \mathrm{C}$, $400{ }^{\circ} \mathrm{C}$, and $800{ }^{\circ} \mathrm{C}$ were selected to be placed in clean water and $5 \% \mathrm{Na}_{2} \mathrm{SO}_{4}$ solution for $28 \mathrm{~d}$. The relevant performance of the UP groups before self-repair can be found in the Sections 3.1-3.3. As the temperature increased, the size and number of cracks also increased. Figure 14 shows the surface of the groups after self-healing. It can be seen from the microscope that in the groups at $200{ }^{\circ} \mathrm{C}$ and $400{ }^{\circ} \mathrm{C}$, due to the initial fewer and finer cracks, white sediment appeared and filled the gaps on the surface. However, in the group at $800{ }^{\circ} \mathrm{C}$, due to the initial more numerous and broader cracks, the filling degree decreased significantly, and the cracks were in a semi-blocked state.

Figure 15a shows the compressive strength after self-healing. When the temperature was $200{ }^{\circ} \mathrm{C}$ and $400{ }^{\circ} \mathrm{C}$, the strength enhancement effect of the specimens in water and the $5 \% \mathrm{Na}_{2} \mathrm{SO}_{4}$ solution was low, less than $10 \%$. Above $800{ }^{\circ} \mathrm{C}$, however, the enhancement effect was significant. Using the results before self-healing as the reference, the improvement rates for the two environments (clean water and $5 \% \mathrm{Na}_{2} \mathrm{SO}_{4}$ solution) were $63.67 \%$ and $65.10 \%$, respectively. It can be found that after $28 \mathrm{~d}$, the recovery results of the two environments for the compressive strength were about the same and there was no significant difference. 


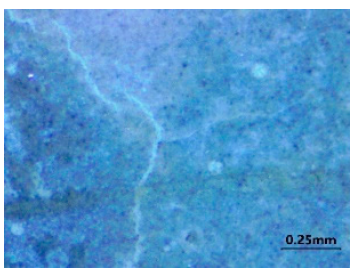

(a) $200{ }^{\circ} \mathrm{C}$

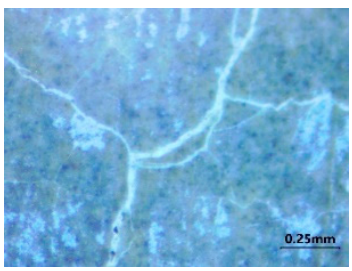

(b) $400{ }^{\circ} \mathrm{C}$

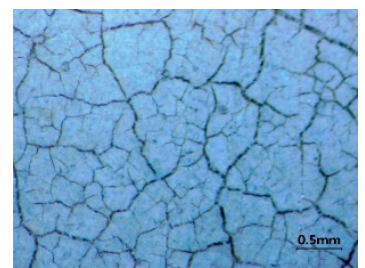

(c) $800{ }^{\circ} \mathrm{C}(75 \times)$

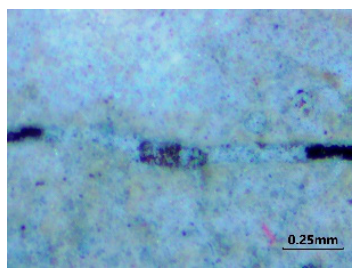

(d) $800{ }^{\circ} \mathrm{C}(150 \times)$

Figure 14. Surface condition after exposure to high temperatures and self-healing under clean water.

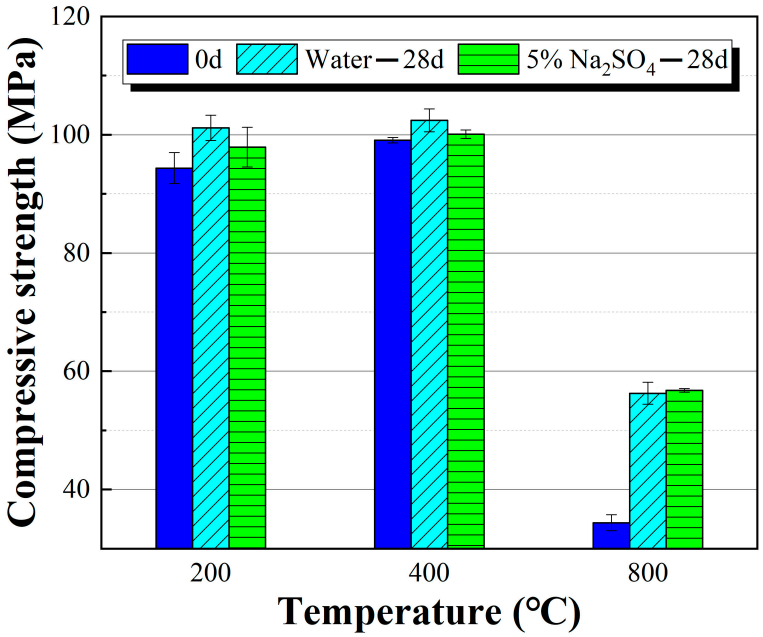

(a) Compressive strength

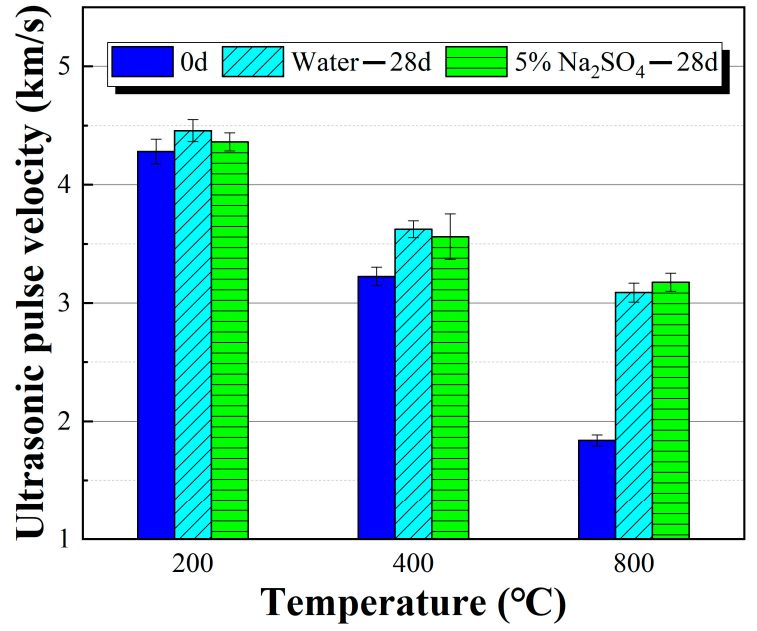

(b) Ultrasonic pulse velocity

Figure 15. Mechanical properties of UHPC after exposure to high temperatures and self-healing.

Figure 15b shows the ultrasonic pulse velocity after self-healing. The changing trend of ultrasonic pulse velocity after self-healing was consistent with the compressive strength. The enhancement was not significant when the temperature was low, while it was significant above $800{ }^{\circ} \mathrm{C}$. There was substantial recovery from $400{ }^{\circ} \mathrm{C}$, and the ultrasonic pulse velocity above $800{ }^{\circ} \mathrm{C}$ was similar to that before self-healing above $400{ }^{\circ} \mathrm{C}$, which shows that the effect of self-healing on ultrasonic pulse velocity was more evident compared with the compressive strength.

\subsubsection{Transport Properties}

Based on the results of compressive strength and ultrasonic pulse velocity, it was initially concluded that self-healing development above $200{ }^{\circ} \mathrm{C}$ and $400{ }^{\circ} \mathrm{C}$ was not that noticeable, and the restoration effect of clean water was slightly more substantial than that of the $5 \% \mathrm{Na}_{2} \mathrm{SO}_{4}$ solution. The impact of self-healing above $800{ }^{\circ} \mathrm{C}$ was significant, and the recovery effect of the $5 \% \mathrm{Na}_{2} \mathrm{SO}_{4}$ solution was marginally stronger than that of clean water. Then, the trend of the performance recovery after exposure to high temperatures was further explored in the RCM and capillary water absorption test.

While there are many reasons for the deterioration of concrete durability, steel corrosion is one of the most dominant forms, and chloride ions are the leading cause of steel corrosion. For this reason, it is necessary to investigate the improvement of the chloride ion attack phenomenon through the self-healing effect. Figure 16 shows the results of RCM tests before and after self-healing, and the degradation of the coefficients is very pronounced. Using the previous data before self-healing as the reference group, the decrease rates above each temperature for the two respective environments (clean water and $5 \%$ $\mathrm{Na}_{2} \mathrm{SO}_{4}$ solution) were $31.58 \%$ and $42.11 \%$ above $200^{\circ} \mathrm{C}, 53.15 \%$ and $52.45 \%$ above $400^{\circ} \mathrm{C}$, and $59.92 \%$ and $59.43 \%$ above $800{ }^{\circ} \mathrm{C}$. 


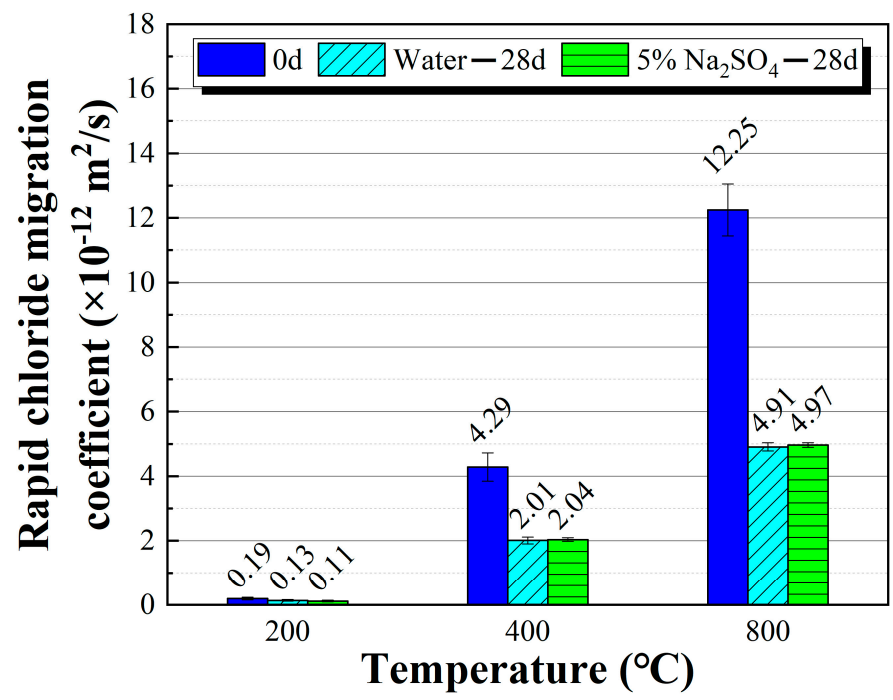

Figure 16. RCM results of UHPC after exposure to high temperatures and self-healing.

The capillary water absorption curves after self-healing are shown in Figure 17, and the initial capillary water absorption coefficients can be obtained according to Equation (5), as shown in Table 5. The initial capillary water absorption coefficients of the different groups all showed various degrees of decreasing trends after going through the self-healing process. With $0 \mathrm{~d}$ of self-healing as the reference group, the initial capillary water absorption coefficients in the respective clean water and $5 \% \mathrm{Na}_{2} \mathrm{SO}_{4}$ solution decreased by $30.00 \%$ and $26.68 \%$ above $200{ }^{\circ} \mathrm{C}, 83.17 \%$ and $66.30 \%$ above $400{ }^{\circ} \mathrm{C}$, and $89.74 \%$ and $69.37 \%$ above $800{ }^{\circ} \mathrm{C}$.

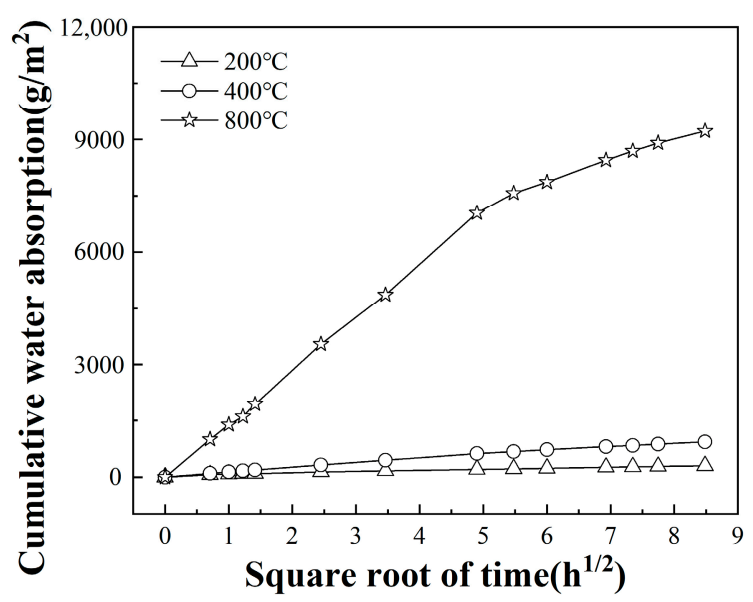

(a) Clean water-28d

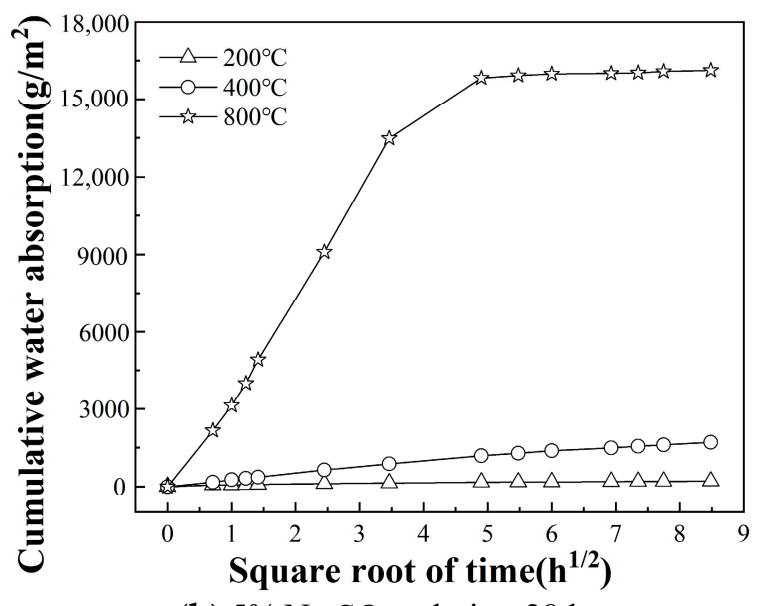

(b) $5 \% \mathrm{Na}_{2} \mathrm{SO}_{4}$ solution- $28 \mathrm{~d}$

Figure 17. Capillary water absorption curves after exposure to high temperatures and self-healing.

Table 5. Initial capillary water absorption coefficient after exposure to high temperatures and selfhealing.

\begin{tabular}{cccc}
\hline Environment & $\mathbf{2 0 0}{ }^{\circ} \mathbf{C}$ & $\mathbf{4 0 0}{ }^{\circ} \mathbf{C}$ & $\mathbf{8 0 0}{ }^{\circ} \mathbf{C}$ \\
\hline None-0 d & 95.20 & 880.87 & $1,6868.97$ \\
Clean water-28 d & 66.64 & 148.25 & 1730.56 \\
$5 \% \mathrm{Na}_{2} \mathrm{SO}_{4}$ solution-28 d & 69.80 & 296.89 & 5166.73 \\
\hline
\end{tabular}

The self-healing environment had little effect below $200{ }^{\circ} \mathrm{C}$. In contrast, the clean water environment was more favorable to the self-healing effect above $400{ }^{\circ} \mathrm{C}$ and $800{ }^{\circ} \mathrm{C}$, 
whose initial capillary absorption coefficient was significantly reduced and substantially lower than that of the $5 \% \mathrm{Na}_{2} \mathrm{SO}_{4}$ solution.

The curves were plotted using Equation (5) and indicated that the change trends after self-healing in different environments were roughly similar and consistent with the previous conclusions (Figure 18). In the early stage, the high capillary absorption coefficient of the reference group resulted from the extensive damage caused by high temperatures. The invaded moisture rapidly increased the internal relative humidity, making it reach the internal humidity equilibrium state quickly, which in turn resulted in the lowest absorption coefficient in the late stage (the interior moisture was close to $100 \%$ ). The self-healing effect extended the internal humidity equilibrium process, thus forming a relative change in the pattern of low in the early stage and high in the late stage.

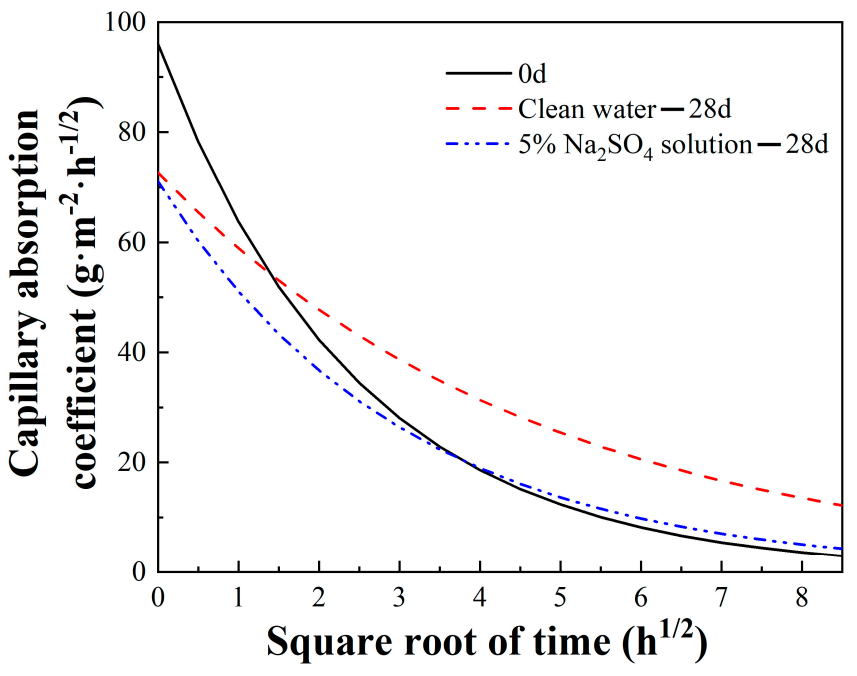

(a) $200^{\circ} \mathrm{C}$

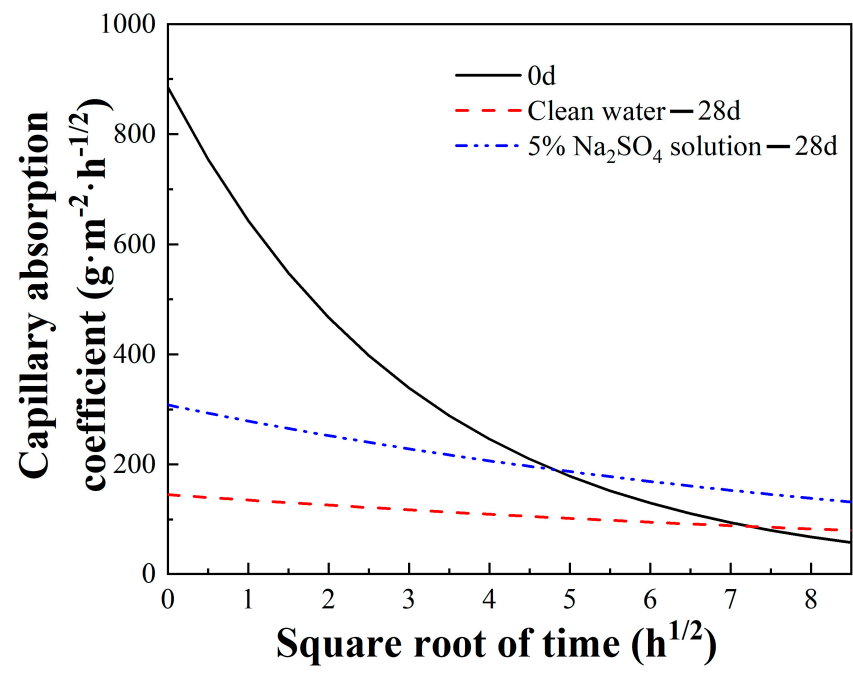

(b) $400{ }^{\circ} \mathrm{C}$

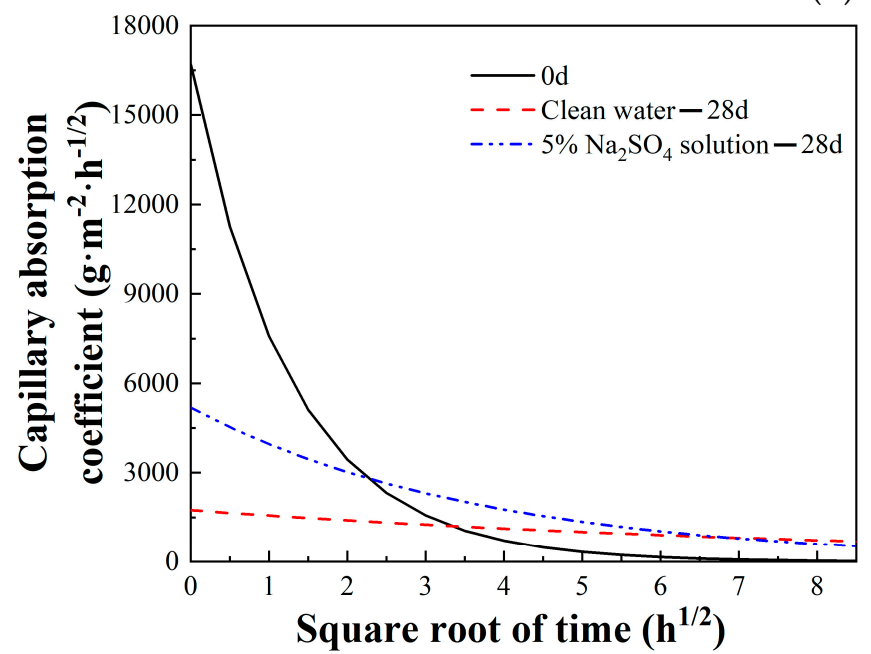

(c) $800{ }^{\circ} \mathrm{C}$

Figure 18. Capillary water absorption coefficient curves after exposure to high temperatures and self-healing.

\subsubsection{Self-Healing Products}

The sample above $800{ }^{\circ} \mathrm{C}$ was selected; the white sediment was scraped off and collected from the surface of the sample with tools after the self-healing period. The results are shown in Figure 19. XRD results show that $\mathrm{CaCO}_{3}$ and $\mathrm{CaSO}_{4} \cdot 2 \mathrm{H}_{2} \mathrm{O}$ were the main self-healing products in different environments, which is consistent with the research results of several scholars $[35,54]$, with a higher characteristic peak of $\mathrm{CaSO}_{4} \cdot 2 \mathrm{H}_{2} \mathrm{O}$ in the $5 \% \mathrm{Na}_{2} \mathrm{SO}_{4}$ solution. 


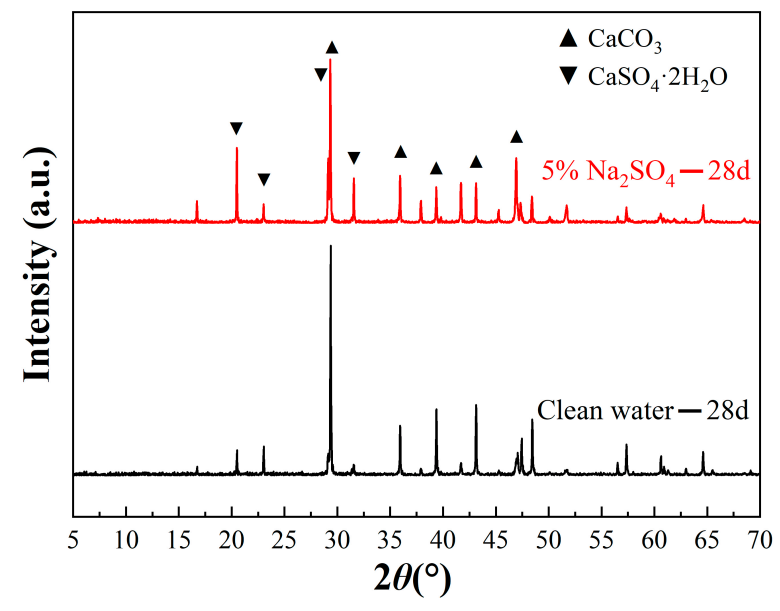

(a) XRD

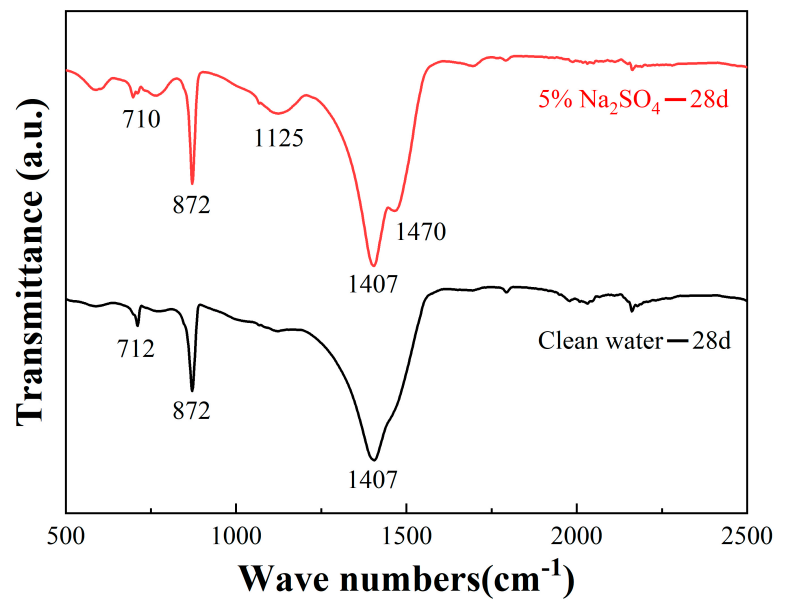

(b) FTIR

Figure 19. XRD\&FTIR patterns of self-healing products.

The $\mathrm{Ca}^{2+}$ and $\mathrm{SO}_{4}{ }^{2-}$ generated by the high-temperature decomposition of hydration products (such as $\mathrm{Ca}(\mathrm{OH})_{2}$, Ettringite, etc.) still exist stably in the matrix. On the one hand, the residual cementitious material is exposed to the outside through cracks and continues to hydrate when it comes into contact with water, generating $\mathrm{Ca}^{2+}$. At the same time, the $\mathrm{CO}_{2}$ in the air dissolves in water and forms $\mathrm{CO}_{3}{ }^{2-}$ in an alkaline environment. Together, they produce $\mathrm{CaCO}_{3}$. The $\mathrm{SO}_{4}{ }^{2-}$ that exists inside the concrete will also generate Gypsum and other substances along with the newly formed $\mathrm{Ca}^{2+}$. On the other hand, the cracks formed after the high temperatures exposure provide a channel for the external environment, facilitating the penetration of $\mathrm{SO}_{4}{ }^{2-}$ from the $5 \% \mathrm{Na}_{2} \mathrm{SO}_{4}$ solution into the interior. The exterior and internal $\mathrm{SO}_{4}{ }^{2-}$ accumulate in the cracks, generating more hydration products such as Gypsum.

The FTIR results indicated that the absorption characteristic peaks of $\mathrm{CaCO}_{3}$ (inplane shear vibration peak at around $712 \mathrm{~cm}^{-1}$, out-of-plane bending vibration peak at $872 \mathrm{~cm}^{-1}$, and antisymmetric absorption peak at $1407 \mathrm{~cm}^{-1}$ ) were mainly present in both environments of the self-healing products, which is consistent with the XRD test results $[54,55]$. The $\mathrm{CaCO}_{3}$ and Gypsum generated by self-healing were deposited and filled in the cracks, contributing to the refinement and even recovery of the damage, and the macroscopic expression is the recovery of mechanical properties and water absorption properties. However, the hydration products such as Ettringite and Gypsum will continue to enrich, grow and swell in the cracks, rapidly generating a considerable crystallization pressure. Over time, this will even exceed the tensile strength of the specimen itself to resist the internal stress, and secondary cracking will eventually occur. Therefore, in terms of the transport properties, the $5 \% \mathrm{Na}_{2} \mathrm{SO}_{4}$ solution environment will be inferior to the clean water environment.

\section{Conclusions}

This work presents the results of experimental investigation on the properties after exposure to elevated temperatures of ultra-high performance concrete with two types of synthetic fibers (PP and PAN fibers) in terms of the mass loss, compressive strength, ultrasonic pulse velocity, transport properties, and micro-structure. An effective approach to improving mechanical and transport properties was found from two types of environments (clean water and $5 \% \mathrm{Na}_{2} \mathrm{SO}_{4}$ solution). The phase compositions responsible for the enhancement of the properties were also determined by XRD and FTIR patterns. The following main conclusions can be drawn based on the results of this research.

(1) Compared to PAN fibers, PP fibers are more effective in preventing the concrete from bursting and are more suitable for high-temperature tests. With the increase in temperature, the compressive strength showed an increase and then decline; the rest of 
the properties (mass loss, surface cracks, ultrasonic pulse velocity, and capillary water absorption) showed the same pattern of change, that is, gradual deterioration and more serious effects. A temperature of $400^{\circ} \mathrm{C}$ was the threshold temperature point for the beginning of a significant decline, where the water absorption performance was more sensitive to temperatures and there was a greater degree of high-temperature deterioration.

(2) During the process of high temperature and self-healing, all the properties rebounded, and the higher the temperature, the wider the crack, and the better the recovery effect. After self-healing, the compressive strength at $800{ }^{\circ} \mathrm{C}$ was about $60 \%$ higher than that before self-healing. Likewise, the water absorption property was more responsive to the degree of post-high temperature recovery. After self-healing, the initial capillary water absorption coefficient in the clean water environment above $800{ }^{\circ} \mathrm{C}$ was $89.74 \%$ lower than that before self-healing.

(3) After the high temperatures, the phase composition and pore structure both changed significantly. The lower temperature (within $400{ }^{\circ} \mathrm{C}$ ) was conducive to further hydration reactions to generate more hydration products and possible crystalline changes, refining the internal pores and optimizing the pore structure, which was macroscopically manifested in the increase in compressive strength.

(4) The main product generated after exposure to high-temperature self-healing was $\mathrm{CaCO}_{3}$. There will also be the presence of Gypsum and other substances; the interaction of the two promotes the refinement and healing of cracks. However, the $5 \% \mathrm{Na}_{2} \mathrm{SO}_{4}$ solution environment promoted generation, which will lead to significant expansion and cause the secondary cracking phenomenon. Therefore, for the self-healing of UHPC after exposure to high temperatures, the $5 \% \mathrm{Na}_{2} \mathrm{SO}_{4}$ solution environment would be inferior to the clean water environment.

Author Contributions: Conceptualization, D.Y. and Z.M.; methodology, D.Y.; validation, Y.Q., Y.X. and H.G.; formal analysis, Y.Q. and Y.X.; investigation, Y.Q., Y.X. and H.G.; writing-original draft preparation, D.Y., Y.Q. and Z.M.; writing—review and editing, Z.M., D.Y., Y.Q. and H.G.; project administration, D.Y. and Z.M.; funding acquisition, D.Y. All authors have read and agreed to the published version of the manuscript.

Funding: The authors gratefully acknowledge the substantial support from the ongoing projects of the National Key R\&D Program of China 2018YFD1101002.

Institutional Review Board Statement: Not applicable.

Informed Consent Statement: Not applicable.

Data Availability Statement: The data presented in this study are available on request from the corresponding author. The data are not publicly available due to a complicated structure that requires additional explanation.

Conflicts of Interest: The authors declare no conflict of interest.

\section{References}

1. Bajaber, M.A.; Hakeem, I.Y. UHPC evolution, development, and utilization in construction: A review. J. Mater. Res. Technol. 2021, 10, 1058-1074. [CrossRef]

2. Shi, C.J.; Wu, Z.M.; Xiao, J.F.; Wang, D.H.; Huang, Z.Y.; Fang, Z. A review on ultra high performance concrete: Part I. Raw materials and mixture design. Constr. Build. Mater. 2015, 101, 741-751. [CrossRef]

3. Yoo, D.Y.; Yoon, Y.S. A Review on Structural Behavior, Design, and Application of Ultra-High-Performance Fiber-Reinforced Concrete. Int. J. Concr. Struct. M. 2016, 10, 125-142. [CrossRef]

4. Liu, J.C.; Tan, K.H. Fire resistance of ultra-high performance strain hardening cementitious composite: Residual mechanical properties and spalling resistance. Cement. Concr. Comp. 2018, 89, 62-75. [CrossRef]

5. Missemer, L.; Ouedraogo, E.; Malecot, Y.; Clergue, C.; Rogat, D. Fire spalling of ultra-high performance concrete: From a global analysis to microstructure investigations. Cement. Concr. Res. 2019, 115, 207-219. [CrossRef]

6. Kodur, V.; Banerii, S. Modeling the fire-induced spalling in concrete structures incorporating hydro-thermo-mechanical stresses. Cement. Concr. Comp. 2021, 117, 103902. [CrossRef]

7. Dwaikat, M.B.; Kodur, V.K.R. Fire Induced Spalling in High Strength Concrete Beams. Fire Technol. 2010, 46, 251-274. [CrossRef] 
8. Kodur, V.K.R.; Phan, L. Critical factors governing the fire performance of high strength concrete systems. Fire Saf. J. 2007, 42, 482-488. [CrossRef]

9. Park, J.J.; Yoo, D.Y.; Kim, S.; Kim, S.W. Benefits of synthetic fibers on the residual mechanical performance of UHPFRC after exposure to ISO standard fire. Cement. Concr. Comp. 2019, 104, 103401. [CrossRef]

10. Zheng, W.Z.; Li, H.Y.; Wang, Y. Compressive behaviour of hybrid fiber-reinforced reactive powder concrete after high temperature. Mater. Des. 2012, 41, 403-409. [CrossRef]

11. Hannawi, K.; Bian, H.; Prince-Agbodjan, W.; Raghavan, B. Effect of different types of fibers on the microstructure and the mechanical behavior of Ultra-High Performance Fiber-Reinforced Concretes. Compos. Part B-Eng. 2016, 86, 214-220. [CrossRef]

12. Bentz, D.P. Fibers, percolation, and spalling of high-performance concrete. ACI Mater. J. 2000, 97, 351-359.

13. Chen, Q.; Zhu, Z.Y.; Ma, R.; Jiang, Z.W.; Zhang, Y.; Zhu, H.H. Insight into the Mechanical Performance of the UHPC Repaired Cementitious Composite System after Exposure to High Temperatures. Materials 2021, 14, 4095. [CrossRef] [PubMed]

14. Yang, J.; Peng, G.F.; Zhao, J.; Shui, G.S. On the explosive spalling behavior of ultra-high performance concrete with and without coarse aggregate exposed to high temperature. Constr. Build. Mater. 2019, 226, 932-944. [CrossRef]

15. Li, Y.; Pimienta, P.; Pinoteau, N.; Tan, K.H. Effect of aggregate size and inclusion of polypropylene and steel fibers on explosive spalling and pore pressure in ultra-high-performance concrete (UHPC) at elevated temperature. Cement. Concr. Comp. 2019, 99, 62-71. [CrossRef]

16. Li, Y.; Tan, K.H.; Yang, E.H. Influence of aggregate size and inclusion of polypropylene and steel fibers on the hot permeability of ultra-high performance concrete (UHPC) at elevated temperature. Constr. Build. Mater. 2018, 169, 629-637. [CrossRef]

17. Wang, D.H.; Shi, C.J.; Wu, Z.M.; Xiao, J.F.; Huang, Z.Y.; Fang, Z. A review on ultra high performance concrete: Part II. Hydration, microstructure and properties. Constr. Build. Mater. 2015, 96, 368-377. [CrossRef]

18. Wang, C.; Yang, C.H.; Liu, F.; Wan, C.J.; Pu, X.C. Preparation of Ultra-High Performance Concrete with common technology and materials. Cement. Concr. Comp. 2012, 34, 538-544. [CrossRef]

19. Wang, C.L.; Xue, G.J.; Zhao, X.B. Influence of Fiber Shape and Volume Content on the Performance of Reactive Powder Concrete (RPC). Buildings 2021, 11, 286. [CrossRef]

20. Abid, M.; Hou, X.M.; Zheng, W.Z.; Hussain, R.R. High temperature and residual properties of reactive powder concrete-A review. Constr. Build. Mater. 2017, 147, 339-351. [CrossRef]

21. Tai, Y.S.; Pan, H.H.; Kung, Y.N. Mechanical properties of steel fiber reinforced reactive powder concrete following exposure to high temperature reaching $800^{\circ} \mathrm{C}$. Nucl. Eng. Des. 2011, 241, 2416-2424. [CrossRef]

22. Ahmad, S.; Rasul, M.; Adekunle, S.K.; Al-Dulaijan, S.U.; Maslehuddin, M.; Ali, S.I. Mechanical properties of steel fiber-reinforced UHPC mixtures exposed to elevated temperature: Effects of exposure duration and fiber content. Compos. Part B-Eng. 2019, 168, 291-301. [CrossRef]

23. Li, Y.; Tan, K.H.; Yang, E.H. Synergistic effects of hybrid polypropylene and steel fibers on explosive spalling prevention of ultra-high performance concrete at elevated temperature. Cement. Concr. Comp. 2019, 96, 174-181. [CrossRef]

24. Ozawa, M.; Parajuli, S.S.; Uchida, Y.; Zhou, B. Preventive effects of polypropylene and jute fibers on spalling of UHPC at high temperatures in combination with waste porous ceramic fine aggregate as an internal curing material. Constr. Build. Mater. 2019, 206, 219-225. [CrossRef]

25. Liang, X.W.; Wu, C.Q.; Su, Y.; Chen, Z.; Li, Z.X. Development of ultra-high performance concrete with high fire resistance. Constr Build. Mater. 2018, 179, 400-412. [CrossRef]

26. Yang, L.; Liu, G.J.; Gao, D.Y.; Zhang, C.X. Experimental study on water absorption of unsaturated concrete: W/c ratio, coarse aggregate and saturation degree. Constr. Build. Mater. 2021, 272, 121945. [CrossRef]

27. Cantero, B.; del Bosque, I.F.S.; Matias, A.; de Rojas, M.I.S.; Medina, C. Water transport mechanisms in concretes bearing mixed recycled aggregates. Cement. Concr. Comp. 2020, 107, 103486. [CrossRef]

28. Bao, J.W.; Li, S.G.; Zhang, P.; Xue, S.B.; Cui, Y.F.; Zhao, T.J. Influence of exposure environments and moisture content on water repellency of surface impregnation of cement-based materials. J. Mater. Res. Technol. 2020, 9, 12115-12125. [CrossRef]

29. Poon, C.S.; Azhar, S.; Anson, M.; Wong, Y.L. Comparison of the strength and durability performance of normal- and high-strength pozzolanic concretes at elevated temperatures. Cement. Concr. Res. 2001, 31, 1291-1300. [CrossRef]

30. Nadeem, A.; Memon, S.A.; Lo, T.Y. Mechanical performance, durability, qualitative and quantitative analysis of microstructure of fly ash and Metakaolin mortar at elevated temperatures. Constr. Build. Mater. 2013, 38, 338-347. [CrossRef]

31. Sideris, K.K.; Manita, P. Residual mechanical characteristics and spalling resistance of fiber reinforced self-compacting concretes exposed to elevated temperatures. Constr. Build. Mater. 2013, 41, 296-302. [CrossRef]

32. Guo, J.Y.; Wang, J.Y.; Wu, K. Effects of self-healing on tensile behavior and air permeability of high strain hardening UHPC. Constr. Build. Mater. 2019, 204, 342-356. [CrossRef]

33. Beglarigale, A.; Eyice, D.; Tutkun, B.; Yazici, H. Evaluation of enhanced autogenous self-healing ability of UHPC mixtures. Constr. Build. Mater. 2021, 280, 122524. [CrossRef]

34. Jiang, J.Y.; Zheng, X.J.; Wu, S.P.; Liu, Z.Y.; Zheng, Q. Nondestructive experimental characterization and numerical simulation on self-healing and chloride ion transport in cracked ultra-high performance concrete. Constr. Build. Mater. 2019, 198, 696-709. [CrossRef]

35. Kim, S.; Yoo, D.Y.; Kim, M.J.; Banthia, N. Self-healing capability of ultra-high-performance fiber-reinforced concrete after exposure to cryogenic temperature. Cement. Concr. Comp. 2019, 104, 103335. [CrossRef] 
36. Li, Y. Effect of post-fire curing and silica fume on permeability of ultra-high performance concrete. Constr. Build. Mater. 2021, 290, 123175. [CrossRef]

37. Zhang, D.S.; Yang, Q.N.; Mao, M.J.; Li, J.B. Carbonation performance of concrete with fly ash as fine aggregate after stress damage and high temperature exposure. Constr. Build. Mater. 2020, 242, 118125. [CrossRef]

38. Wroblewski, R.; Stawiski, B. Ultrasonic Assessment of the Concrete Residual Strength after a Real Fire Exposure. Buildings 2020, 10, 154. [CrossRef]

39. Ma, Z.M.; Yao, P.P.; Yang, D.Y.; Shen, J.S. Effects of fire-damaged concrete waste on the properties of its preparing recycled aggregate, recycled powder and newmade concrete. J. Mater. Res. Technol. 2021, 15, 1030-1045. [CrossRef]

40. Wu, H.X.; Yang, D.Y.; Xu, J.G.; Liang, C.F.; Ma, Z.M. Water transport and resistance improvement for the cementitious composites with eco-friendly powder from various concrete wastes. Constr. Build. Mater. 2021, 290, 123247. [CrossRef]

41. Bao, J.W.; Xue, S.B.; Zhang, P.; Dai, Z.Z.; Cui, Y.F. Coupled effects of sustained compressive loading and freeze-thaw cycles on water penetration into concrete. Struct. Concr. 2020, 22, E944-E954. [CrossRef]

42. Zhang, P.; Wittmann, F.H.; Vogel, M.; Muller, H.S.; Zhao, T.J. Influence of freeze-thaw cycles on capillary absorption and chloride penetration into concrete. Cement. Concr. Res. 2017, 100, 60-67. [CrossRef]

43. Wu, H.X.; Xiao, J.Z.; Liang, C.F.; Ma, Z.M. Properties of Cementitious Materials with Recycled Aggregate and Powder Both from Clay Brick Waste. Buildings 2021, 11, 119. [CrossRef]

44. Elfmarkova, V.; Spiesz, P.; Brouwers, H.J.H. Determination of the chloride diffusion coefficient in blended cement mortars. Cement. Concr. Res. 2015, 78, 190-199. [CrossRef]

45. Ferdosian, I.; Camoes, A. Mechanical performance and post-cracking behavior of self-compacting steel-fiber reinforced ecoefficient ultra-high performance concrete. Cement. Concr. Comp. 2021, 121, 104050. [CrossRef]

46. Soltanzadeh, F.; Cunha, V.M.C.F.; Barros, J.A.O. Assessment of different methods for characterization and simulation of postcracking behavior of self-compacting steel fiber reinforced concrete. Constr. Build. Mater. 2019, 227, 116704. [CrossRef]

47. Sanchayan, S.; Foster, S.J. High temperature behaviour of hybrid steel-PVA fibre reinforced reactive powder concrete. Mater. Struct. 2016, 49, 769-782. [CrossRef]

48. Gong, J.Q.; Deng, G.Q.; Shan, B. Performance evaluation of RPC exposed to high temperature combining ultrasonic test: A case study. Constr. Build. Mater. 2017, 157, 194-202. [CrossRef]

49. Wang, D.; Yang, P.; Hou, P.K.; Zhang, L.N.; Zhou, Z.H.; Cheng, X. Effect of $\mathrm{SiO}_{2}$ oligomers on water absorption of cementitious materials. Cement. Concr. Res. 2016, 87, 22-30. [CrossRef]

50. Zhang, D.; Dasari, A.; Tan, K.H. On the mechanism of prevention of explosive spalling in ultra-high performance concrete with polymer fibers. Cement. Concr. Res. 2018, 113, 169-177. [CrossRef]

51. Liu, P.; Cui, S.G.; Li, Z.H.; Xu, X.F.; Guo, C. Influence of surrounding rock temperature on mechanical property and pore structure of concrete for shotcrete use in a hot-dry environment of high-temperature geothermal tunnel. Constr. Build. Mater. 2019, 207, 329-337. [CrossRef]

52. Bangi, M.R.; Horiguchi, T. Pore pressure development in hybrid fibre-reinforced high strength concrete at elevated temperatures. Cement. Concr. Res. 2011, 41, 1150-1156. [CrossRef]

53. Peng, G.F.; Niu, X.J.; Shang, Y.J.; Zhang, D.P.; Chen, X.W.; Ding, H. Combined curing as a novel approach to improve resistance of ultra-high performance concrete to explosive spalling under high temperature and its mechanical properties. Cement. Concr. Res. 2018, 109, 147-158. [CrossRef]

54. Zhang, X.J.; Fan, X.D.; Li, M.; Samia, A.; Yu, X. Study on the behaviors of fungi-concrete surface interactions and theoretical assessment of its potentials for durable concrete with fungal-mediated self-healing. J. Clean. Prod. 2021, 292, 125870. [CrossRef]

55. Legodi, M.A.; de Waal, D.; Potgieter, J.H.; Potgieter, S.S. Rapid determination of CaCO3 in mixtures utilising FT-IR spectroscopy. Miner. Eng. 2001, 14, 1107-1111. [CrossRef] 